\title{
THE IMPACT OF GLOBAL BUDGETING ON TREATMENT INTENSITY AND OUTCOMES*
}

\author{
Kamhon Kan ${ }^{a, b} \quad$ Shu-Fen Lib,c Wei-Der Tsai ${ }^{b}$ \\ March 14, 2011
}

\begin{abstract}
In this study, we use patient level data to examine the intensity of treatment received by patients suffering acute myocardial infarction (AMI), ischemic heart disease, hemorrhagic stroke, and ischemic stroke patients, and their health outcomes after treatment in Taiwan, where global budgets for hospitals were launched in 2002. We find that the launch of global budgets has led to an increase in the intensity of treatment received by patients admitted to a for-profit hospital and not very much improvement in their health outcomes. These results indicates that the increase in treatment intensity represent a misallocation or waste of resources.
\end{abstract}

Keywords: Global budget, Treatment outcomes, Regression discontinuity design, AMI , Ischemic heart disease, Hemorrhagic stroke, I schemic stroke

J EL Classification: I11, |18, I31

*We thank Ruei-Hua Wang and Tsai-Ling Li for able research assitance. Please address correspondence to Wei-Der Tsai, Graduate Institute of Industrial Economics, Chungli, Taiwan 32001; (t) 886-3-4227151x66473;

(e) twd@cc.ncu.edu.tw.

a nstitute of Economics, Academia Sinica, Taiwan.

${ }^{\mathrm{b}}$ Graduate Institute of Industrial E conomics, National Central University, Taiwan.

'Department of International Business, Central Taiwan University of Science and Technol ogy, Taiwan. 


\section{Introduction}

This study investigates the impact of global budgeting on the intensity of treatment received by patients and their health outcomes. In developed or high income countries, governments play an important role in financing health care services through the public provision of health insurance or direct provision of health care services, or through subsidizing the utilization of medical services (see Docteur and Oxley, 2004). Thus, the rapid increase in health care expenditure since the 1960s has become a great concern to policy makers in these countries. In response to soaring health care costs, various cost containment measures have been implemented. These cost containment measures can be classified into four categories, namely, "budget shifting”, "budget setting”, "control”, and "competition" (see Le Grand, 2003). ${ }^{1}$ According to Le Grand (2003), among these cost containment measures, budget setting (i.e., global budgeting, a supply-sided method) is the most effective measure. Because global budgeting is effective in controlling medical expenditures, it is widely adopted in OECD countries (see Docteur and Oxley, 2004, and Wolfe and Moran, 1993).

The literature is silent on this issue even though it is important. While global budgeting aims at curbing the growth in health care expenditure and it is shown to be effective in doing so, it is undear what effect global budgeting has on treatment intensity and whether successful cost containment is at the expense of patients welfare. If medical cost containment by global budgeting is accompanied by a decrease in patient welfare arising from worsening treatment outcomes, then the health authority should consider alternative cost containment methods or complemental measures to mi nimize this collateral damage. Alternatively, if the implementation of global budgets leads to an increase in treatment intensity, while treatment outcomes do not improve, there is a misallocation or a waste of medical resources and the use of global budgets as a containment device should be reconsidered.

Theoretical studies show that global budgeting is likely to lead to an increase in the quantity of services supplied by providers under reasonable settings. See Fan et al. (1998)

\footnotetext{
${ }^{1}$ Co-payment and restriction on the types of treatment to be reimbursed are examples of "budgeting shifting"; global budgeting is a form of "budget setting"; "control" refers to various forms of regulations on way medical services are provided (e.g., managed care and the reference system); and "competition" refers to the inducement of competition among insurers or service providers in order to achieve greater efficiency.
} 
and Benstetter and Wambach (2006). The findings of empirical studies of global budgeting on provider's behavior suggest that patients receive a higher level of services, in the form of a larger quantity of services, more intensive service, or more expensive services. This implies that patients may be better off with the implementation of a global budget on health care expenditure.

The data we use come from the $\mathrm{NHI}$ claim records, which is maintained and distributed by Taiwan's National Health Research Institute. Our data covers the period 2000-2005. We examine the treatment outcomes of AMI (acute myocardial infarction), ischemic heart disease, hemorrhagic stroke, and ischemic stroke patients. ${ }^{2}$ Our data consist of the universe of patients hospitalized due to these four diseases in Taiwan during the period 2000-2005. We use the total number of points that a hospital earns from treating a patient as a measure of treatment intensity. ${ }^{3}$ For treatment outcomes, we use patient mortality 7,30 , and 90 days after discharge, and the incidence of readmissions as proxies.

The reason why we focus on the four diseases is that they are the leading causes of mortality in Taiwan and their treatment expenditure account for a large share of health expenditures. Another reason why we study treatment outcomes of these four diseases is that their onset is usually sudden and rapid such that a patient is usually admitted to the nearest hospital. Thus, sorting of patients to certain kinds of hospitals, e.g., patients of higher socioeconomic status being admitted into better hospitals or patients with more severe conditions are admitted to a better equipped hospital, is less likely. Moreover, since these four diseases are usually acute and severe, the treatment outcomes of these diseases are relatively straightforward to measure, e.g., through mortality and readmission.

Moreover, in our analysis, we divide hospitals into for-profit and not-for-profit hospitals. This is because the objectives of these two types of hospitals are likely to be very different. While for-profit hospitals are, to a larger extent, profit-maximizing, not-for-profit hospitals

\footnotetext{
${ }^{2}$ The ICD codes of AMI and ischemic heart disease are 410 and $411-413$, respectively, and that of ischemic stroke and hemorrhagic stroke, respectively, are 434 and 430-431.

${ }^{3} \mathrm{H}$ ospitals earn a number of points by performing a given medical procedure. The number of points associated with a medical procedure reflects the procedure's cost. The total reimbursement that a hospital receives from the Bureau of $\mathrm{N}$ ational Health Insurance equals the unit price (or point value) times the total number of points that it earns.
} 
are more likely to cherish service quality and avoid deficit. It is expected that for-profit hospitals will be more responsive than not-for-profit hospitals to the launch of global budgets. For not-for-profit hospitals since profit making is not their utmost concern, their response to global budgeting is likely to be sluggish. Please refer to Section 3 for a description of these two types of hospitals in Taiwan.

Using the universe of Taiwan's patients hospitalized due to AMI, ischemic heart diseases, hemorrhagic strokes, and ischemic strokes, we find that after the installation of gl obal budgets patients received substantially more treatments in for-profit hospitals, but not for those admitted to not-for-profit hospitals. However, among patients admitted to for-profit hospitals, there was no discernible improvement in mortality and only a slight improvement in the re-admission rates for AMI patients. For patients admitted to not-for-profit hospitals, there were no changes in their treatments quantities and outcomes.

The remaining part of the paper is organized as follows. Section 2 contains a review of the related literature. Section 3 provides the background about Taiwan's National Health Insurance and its global budgets. Section 4 gives detail of the data that we employ for our empirical analysis. Section 5 describes our empirical strategy and reports our results. Section 6 concludes.

\section{Literature Review}

Even though global budgeting is widely adopted as a medical cost contain measure, its economic implications are not well explored in the literature. Moreover, most studies on the subject focus mainly on the behavioral response of providers. Their results implies that, if the medical market is competitive, a larger quantity of medical services is provided under a global budget system, while a smaller amount of services is provided if providers have market power.

While not directly comparing the outcomes of a fee-for-service and a global budget system, Feldman and Lobo's (1997) model indicates that the excess demand, which is typical under global budget systems, is due to the high level of resource intensity chosen by 
providers. This implies that providers improve their service quality in response to global budgeting. This result may be driven by the assumption that providers' utility is a function of service quantity and quality, but not profit.

An early study of the consequences of global budget as a cost containment device is Fan et al. (1998). The paper compares the quantity of physician services under a gl obal budget system and a expenditure target system, where physicians are paid a fixed fee for each unit of services and the total service quantity is fixed by the budget. The theoretical results show that, given the same amount of medical expenditure, providers will provide a larger quantity of services under a global budget system if there is a large number of providers and they act competitively (i.e., do not coordinate with each other). If providers do coordinate, the results depends on the penalty imposed by the government for services supplied beyond the quota under the expenditure target system. These predictions are supported by experimental results.

Medical service providers' behavior under the global budget system and fee-for-service system in a competitive medical care market is analyzed by Benstetter and Wambach (2006). It is shown that under the fee-for-service system, depending on the price (i.e., point-value) of services set by the government, a provider will behavior either as a profit maximizer or a target income pursuer. If the price is above a threshold providers will be profit maximizers and provide more services with an increase in price. Conversely, they will be target income pursuers responding to an increase in price by an increase in the quantity of services supplied in order to maintain a given level of income when the price below the threshold.

Benstetter and Wambach (2006) further show that under a gl obal budget system, providers behave similarly, with the exception that a provider's quantity of services supplied depends on the expected price, which in turn depends on the aggregate quantity of services supplied by all providers in the system. They explains that the low price equilibrium is likely to be attained such that providers pursue a target income. This is because it is less risky for a provider to assume that the price is low and provide a large quantity of services. They cite the case of Germany, which switches from a fee-for-service system to a global budget system and sees a large increase in the quantity of services provided by physicians, to motivate 
their study and support their condusion.

By contrast, Mougeot and Naegelen (2005) consider a setting where providers choose the levels of service quality and cost-minimization effort to maximize profit, patients' quantity demanded for medical services increases with service quality, and the government manipulates the size of the budget to achieve maximum social welfare. The results suggest that compared with a cost-reimbursement (i.e., fee-for-service) system, an expenditure cap results in a lower level of service quality, implying a lower level of equilibrium quantity of services provided and social welfare. These results prevails in monopolistic as well as Cournot-competitive markets.

It is likely that the difference in Mougeot and Naegelen's (2005) results from others reviewed above is due to their assumptions on the strategic behavior of the government and that the levels of service quality and cost-minimization effort, instead of the quantity services, are providers' choice variables. It is questionable whether in reality the government sets the size of the budget strategically and providers choose the level service quality to maximize profit. The differences in Mougeot and Naegelen's (2005) results from other studies also arise from the benchmark they use. Mougeot and Naegelen (2005) use the first-best solution to a fee-for-service system where the government sets the unit price of medical services to maximize social welfare. The use of this benchmark for comparison is theoretically sound, but may not be realistic given that the unit price of medical services may be not set in the way assumed by the paper.

The above review of theoretical studies on the effect of gl obal budget indicates that under reasonable assumptions, as shift of the payment system from fee-for-service to global budget may lead to an increase in the quantity of medical services supplied. In general, findings of empirical studies on the impact of gl obal budgets support this prediction.

The empirical studies in the gl obal budget literature show that medical service providers will increase the quantity or intensity of services under global budgets. For example, in response to an expenditure cap, physicians in Quebec increased their activity levels, and provide more complex and high-priced procedures (see Rochaix, 1993). Similarly, the study 
of Hurley et al. (1997) suggest that expenditure cap in Canada led to an increase in expenditure. ${ }^{4}$ In response to a gl obal budget, dentists in Taiwan exhibit similar behavior (see Lee and J ones, 2004). Also, hospitals in Taiwan are more likely to hospitalize patients under global budgeting, see, e.g., Chen et al. (2007) and Cheng et al. (2009).

\section{Background}

\subsection{National Health Insurance and Hospital Global Budget in Tai- wan}

Since March 1995 National Health Insurance (NHI) provides insurance coverage to all residents in Taiwan. The medical benefits of Tai wan's NHI is comprehensive, covering inpatient care, ambulatory care, emergency care, laboratory testing, diagnostic imaging, prescription, certain over-the-counter medications, dental care, Chinese medications, preventive care (e.g., pediatric immunization and adult health examination), etc. Taiwan's NHI has substantially reduced the out-of-pocket expenditure of medical service utilization. For example, to see the doctor at a community clinic, a patient pays an appointment fee of NT\$100 and a copayment of NT $\$ 50 .^{5}$

Over ninety percent of hospitals in Tai wan are contracted NHI medical service providers. Initially, $\mathrm{NHI}$ contracted providers are reimbursed on a fee-for-service (FFS) basis. ${ }^{6}$ Under this payment system, a provider is credited a certain point for each treatment procedure offered and each point is worth one New Tai wanese dollar. ${ }^{7}$

The low out-of-pocket user costs allow liberal use of medical services by the general public. The FFS payment system also encourages medical service providers to provide as

\footnotetext{
${ }^{4}$ The cases of Alberta and Scotia Nova are examined. It is found that only Scotia Nova displayed an increase in utilization. Hurely et al. (1997) attribute the absence of utilization increase in Alberta to the favorable political environment and the consultative approach of the implementation of the expenditure cap such that there were trust and good will between Alberta's health authority and its physicians.

${ }^{5}$ That is, US $\$ 3.17$ and US\$1.58, respectively. These are very small amount given that Taiwan's 1995 per capita GDP is NT\$333,948 (US\$12,161).

6 It is also known as the cost-plus system, where providers earn a premi um above the cost of the services they provide.

${ }^{7}$ On average one US Dollar is worth 31.556 New Taiwan Dollars in 2008.
} 
Figure 1: Medical Regions in Taiwan

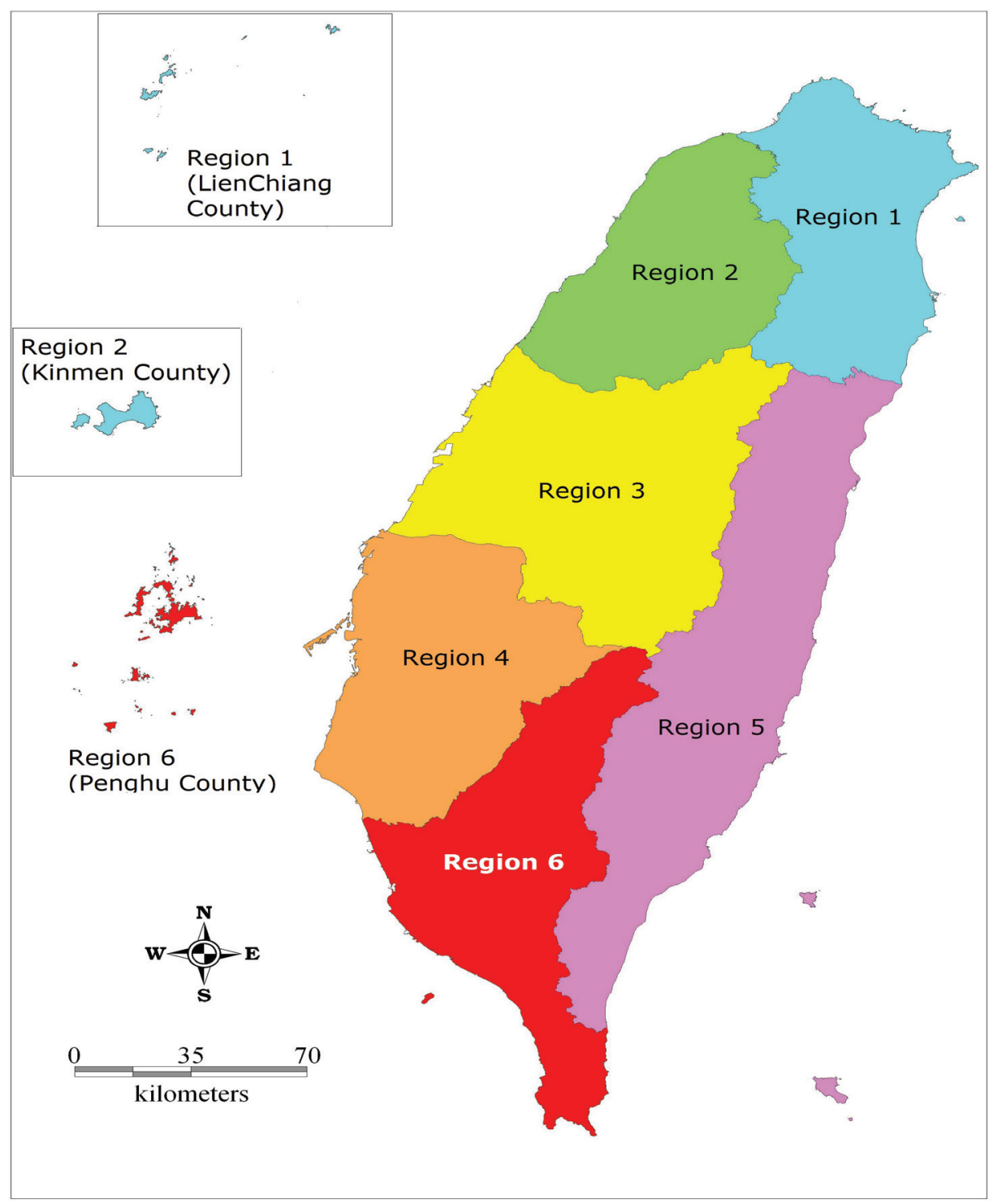


much service as possible. This has led to a rapid growth in health care expenditure and the NHI system has incurred huge deficit. Over the six year period 1996-2001, on average the annual growth rate of expenditure incurred by the $\mathrm{NHI}$ system is $7.43 \%$, and over the 19962001 period the $\mathrm{NHI}$ system accumulated a deficit of NT $\$ 12.82$ billion. This has cast doubt on the long-term financial sustainability of the system, and eventually global budgets were installed to contain the rising health expenditure. Global budgeting was used for dental services starting from 1998. This was followed by global budgets for Chinese Medicine in 2000 , and community clinics in 2001 . Global budgets for all hospital services (i.e., including inpatient and outpatient services) were set in place in 2002.

Under the global budgeting system for hospitals in Taiwan, while there is no hospital level expenditure cap, there is a regi onal one. The whole country is divided into six medical regions. Figure 1 shows the geographical regions covered by the six medical regions. Some basic characteristics of the six medical regions are displayed in Table 1. The largest region, Region 1, in the Northern and North-E astern part of Tai wan, had a population of 7.2 million and 132 hospitals in 2002. The smallest one, Region 5, in the Eastern part of Taiwan, had a population of 0.60 million and 19 hospitals.

The Herfindahl-Hirschman Index, which is calculated based on the number of hospital beds, reported in Table 1 suggests the lack of market power for a single hospital in any of the medical regions. ${ }^{8}$

It is predicted by Fan et al. (1998) and Benstetter and Wambach (2006) that there will be an increase in the quantity of service provided by providers when global budgets are instituted. This prediction is borne out according our preliminary data analysis. The increase in the quantity of medical services supplied is succinctly demonstrated by the increase in the intensity of treatment per patient exhibited in Figure 2, which display the number of points filed per patient for all hospitalized patients, AMI patients, ischemic heart disease patients, hemorrhagic stroke patients, and ischemic stroke patients. We see that there is a

\footnotetext{
8 If a market has a Herfindahl-Hirschman Index exceeding 1800, it is considered to be highly concentrated. Region 5 has the largest Herfindahl-Hirschman Index, 1105.96, which being in the range 1000-1800 is regarded as moderately concentrated according to US standard. However, it is still unlikely that hospitals is able to manipulate the market in Region 5. SeeSection 1.5 of US Department of J ustice and the Federal Trade Commission (1997).
} 
Table 1: Characteristics of the Six Medical Regions in Taiwan as of 2002.*

\begin{tabular}{|c|c|c|c|c|}
\hline Region & $\begin{array}{l}\text { Number of } \\
\text { Hospitals }\end{array}$ & $\begin{array}{c}\text { Herfindahl- } \\
\text { Hirschman Index }\end{array}$ & $\begin{array}{c}\text { Population } \\
\text { Size }\end{array}$ & Cities/Counties Covered \\
\hline Region 1 & 132 & 254.28 & $7,206,555$ & $\begin{array}{l}\text { Taipei City, Taipei County, } \\
\text { Keelung City, Ilan County, } \\
\text { Kinmen County, Lienchi- } \\
\text { ang County (Northern and } \\
\text { North-E Estern Tai wan and } \\
\text { some N orthern outlying is- } \\
\text { lands) }\end{array}$ \\
\hline Region 2 & 66 & 566.98 & $3,184,845$ & 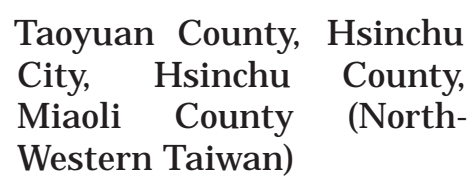 \\
\hline Region 3 & 114 & 302.81 & $4,365,966$ & $\begin{array}{l}\text { Taichung City, Taichung } \\
\text { County, Changhua County, } \\
\text { Nantou County (N orthern } \\
\text { Central Taiwan) }\end{array}$ \\
\hline Region 4 & 99 & 328.33 & $3,425,762$ & $\begin{array}{l}\text { Yunlin County, Chiayi City, } \\
\text { Chiayi County, Tainan City, } \\
\text { Tainan County (Southern } \\
\text { Central Taiwan) }\end{array}$ \\
\hline Region 5 & 19 & 1105.96 & 596,119 & $\begin{array}{l}\text { Taitung County, Hualien } \\
\text { County (Eastern Taiwan) }\end{array}$ \\
\hline Region 6 & 132 & 319.22 & $3,741,529$ & $\begin{array}{l}\text { Kaohsiung City, Kaohsiung } \\
\text { County, Pingtung County, } \\
\text { Penghu County (Southern } \\
\text { Taiwan and South-Western } \\
\text { outlying islands) }\end{array}$ \\
\hline
\end{tabular}

*Hospitals of Chinese Medicine are excluded.

**Market share is computed based on the number of hospital beds. 
Figure 2: Treatment intensity measured by average number of points per inpatient

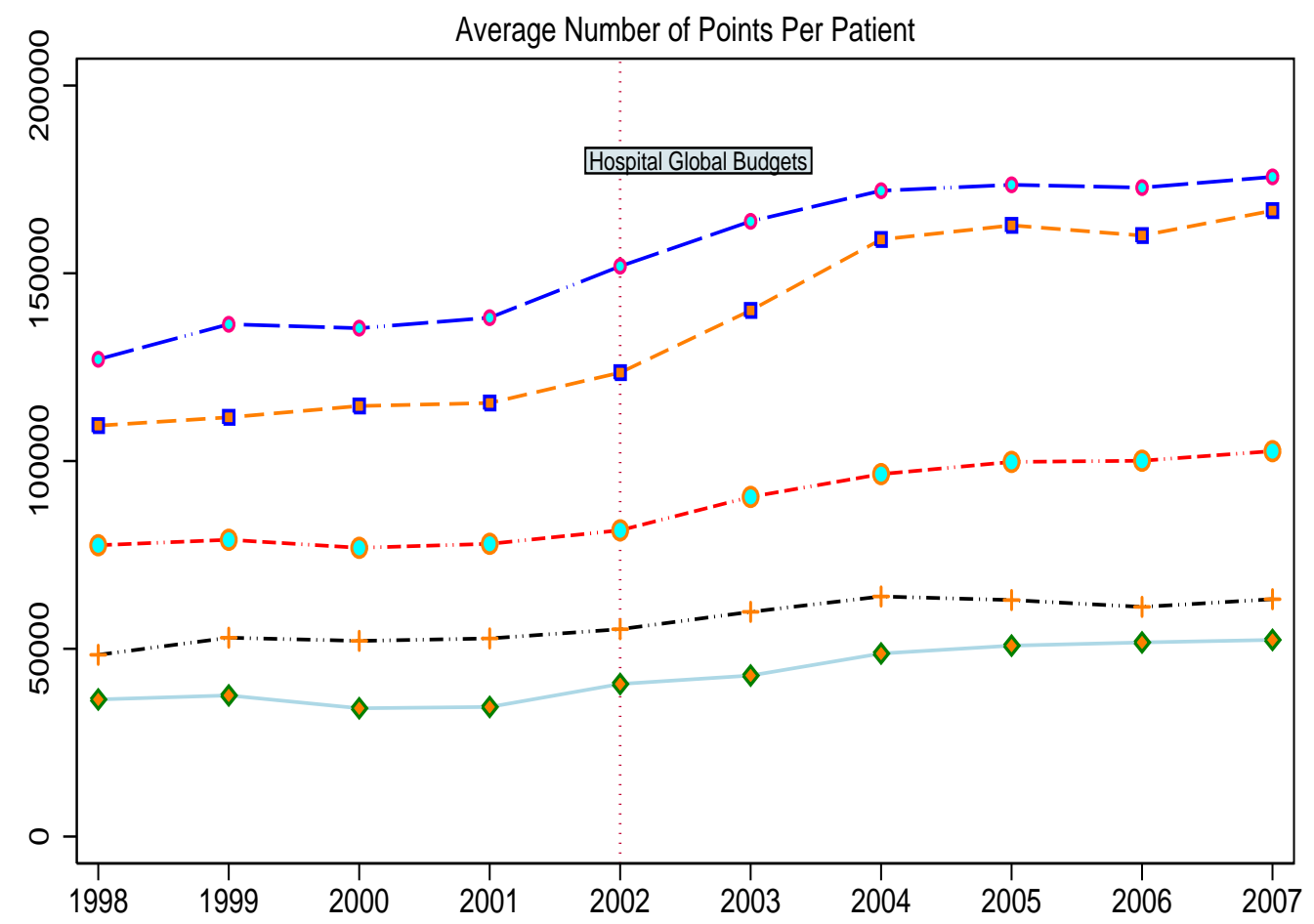

\begin{tabular}{|c|c|c|}
\hline$\diamond \quad$ All Patients & $--\square--$ AMI & - - - - Hemorrhagic Stroke \\
\hline -.+ Ischemic Stroke & ---০--- Ischemic Heart Disease & \\
\hline
\end{tabular}

big jump in the average number of points per patient filed by providers. Another indication of the increase in the quantity of service supplied by providers after the implementation of global budgeting is the sharp increase in the use of more expensive treatment methods, e.g., PTCA (percutaneous transluminal coronary angioplasty) and CABG (coronary artery bypass graft), and the sharp decrease in the use of less expensive treatment methods, i.e., medical management in treating AMI patients. See Figure 3.

A medical region's expenditure cap for a given year is determined at the beginning of the year through consultation with hospitals and taking into account the level of medical expenditure of the previous year. Like the pre-global budget era, each hospital is offered a certain number of points for a service item. However, the point value (i.e., the amount of money that a hospital is reimbursed for each point earned) is uncertain, depending on the 
Figure 3: Treatment of AMI patients

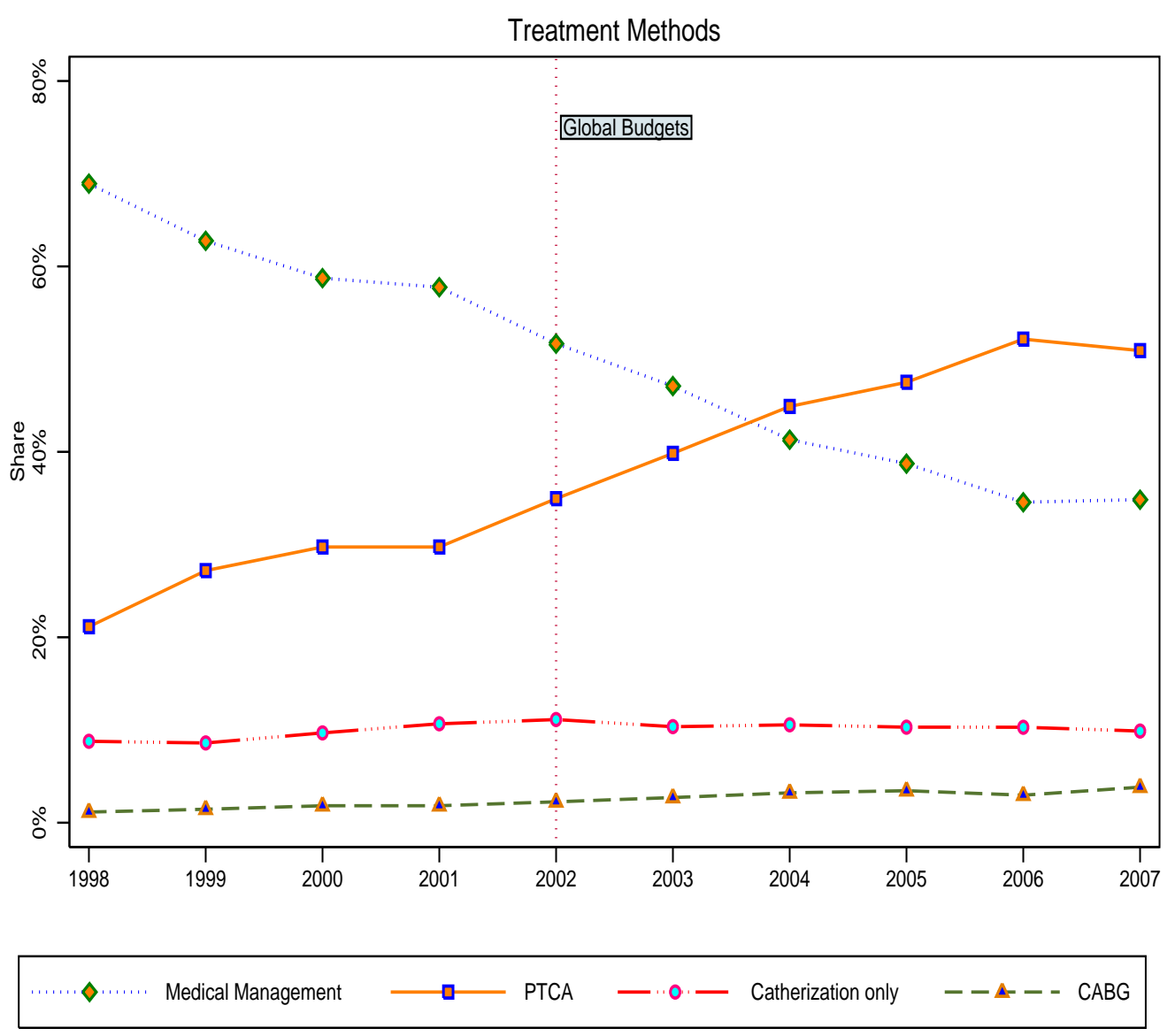

total volume of services provided by hospitals in that medical region. The point value for a given region is determined as follows

$$
\text { point value }=\frac{\text { expenditure cap }}{\sum_{j} \text { volume of service } j \times \text { unit price (points) of service } j} \text {. }
$$

Global budgeting is effective in containing health care costs. Over the period 2002-2007, the average growth in the health expenditure incurred by the $\mathrm{NHI}$ is $4.82 \%$, in contrast to 7.43\% for the period 1997-2001. The effectiveness of global budgeting on cost containment in Taiwan is evident in Figure 4, which shows that after the 2002 implementation of global budgeting the actually $\mathrm{NHI}$ medical expenditure is lower than the projected expenditure, which is based on the pre-2002 expenditure's trend. Since service quantity has increased substantially, while expenditure is allowed to grow at a controlled rate, there is a decrease 


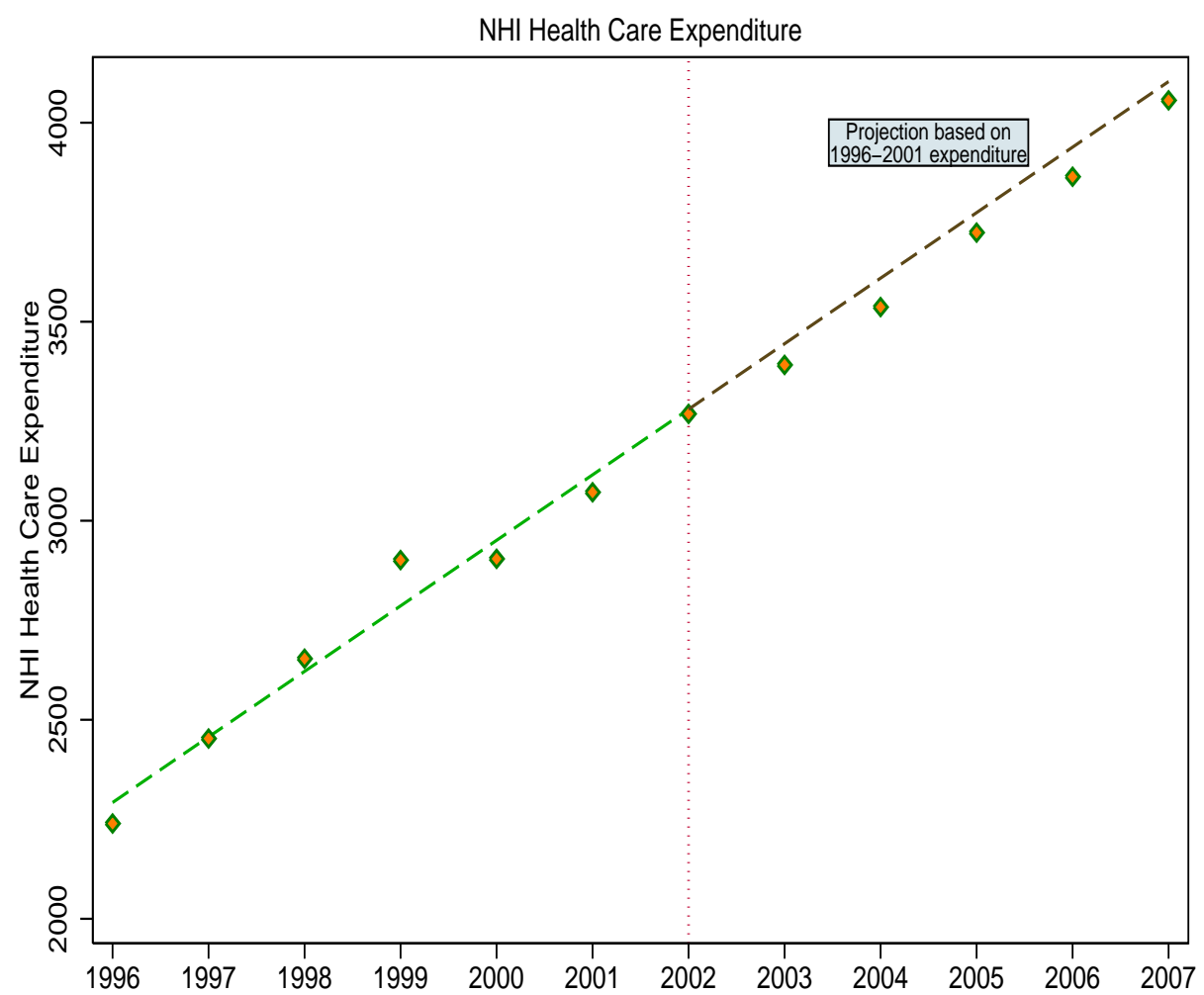

in point value, as showed in Figure 5.

\subsection{For-Profit and Not-For-Profit Hospitals in Taiwan}

In Taiwan, hospitals can be broadly classified into two types, for-profit hospitals and notfor-profit hospitals. The establishment and operation of hospitals in Taiwan are governed by its Medical Law. According to this law, for-profit hospitals are established and run by physicians. As for not-for-profit hospitals, there are two types. One funded and run by the government or public universities, the other is established and run by private not-forprofit corporations, e.g., religious corporations and charitable organizations, which may be partially supported by private donations. A hospital run by a not-for-profit corporations are controlled by a board. It enjoys property tax exemption, and profit tax exemption if over $80 \%$ of it earnings are spent.

Table 2 and Figure 6a, respectively, exhibit the numbers of different types of hospitals and these hospitals' total numbers of beds for years 1998-2008. From Table 2 we see that 
Figure 5: Point Value*

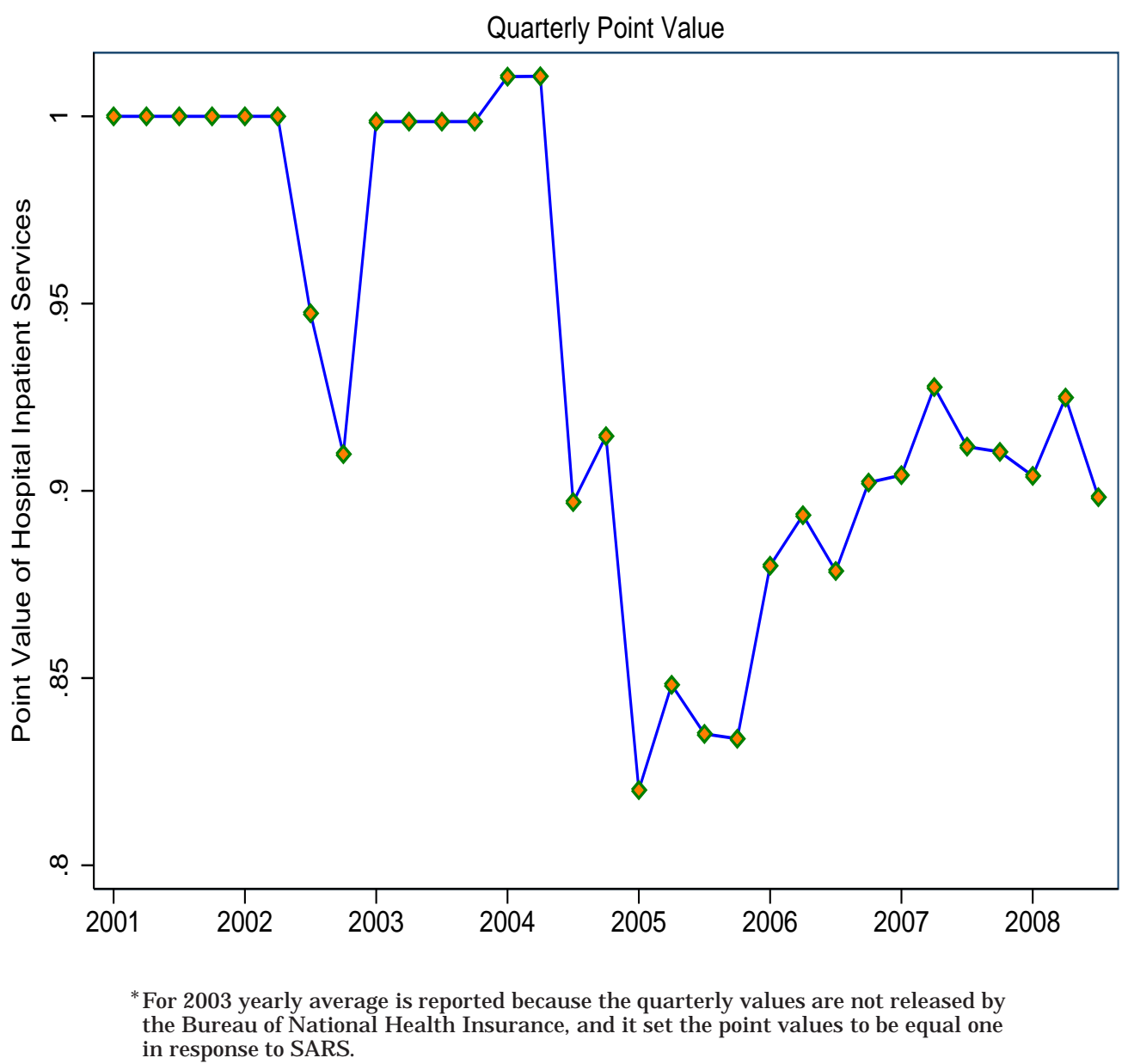

there are far more for-profit hospitals than not-for-profit (i.e., public and private not-forprofit) hospitals, even though their number dedined steadily over the period 1998-2008. However, even though over seventy percent of hospitals in Taiwan are for-profit hospitals, Figure 6a shows that in terms of hospitals beds, for-profit hospitals' total number of beds accounted for less than forty percent of the total number of hospital beds. This suggests that for-profit hospitals are much smaller than not-for-profit hospitals.

Figure $6 \mathrm{~b}$ shows the average number of physicians per bed in different types of hospitals. On average the ratio is higher in private not-for-profit hospitals. For-profit hospitals has the lowest physician per bed ratio. This implies that on average for-profit hospitals devote less resources per patient than private not-for-profit or public hospitals. 
Figure 6: Market share and physicians per bed of different types of hospitals

(a): Market shares of hospital beds

Percentage of total hospital beds

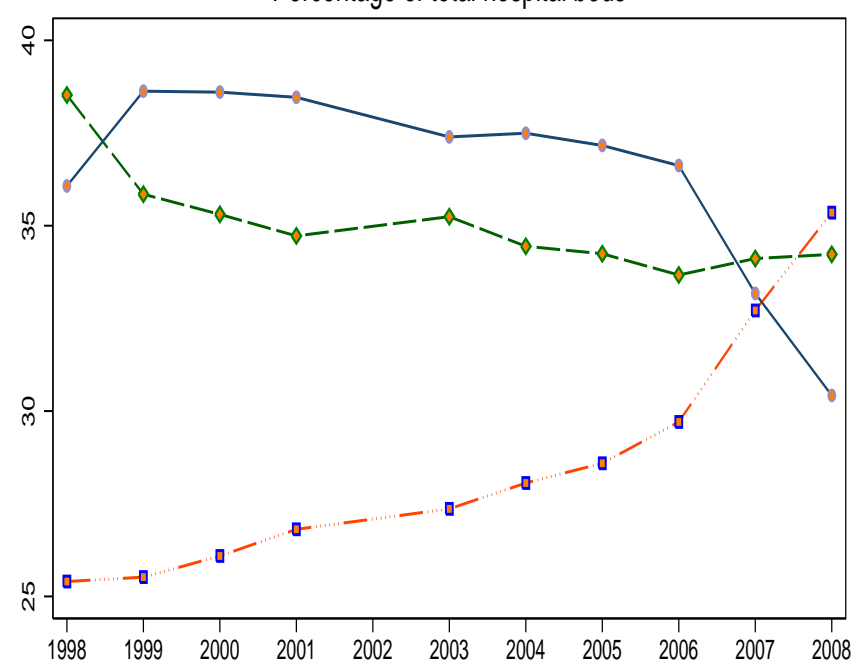

(b): Number of physicians per hospital bed

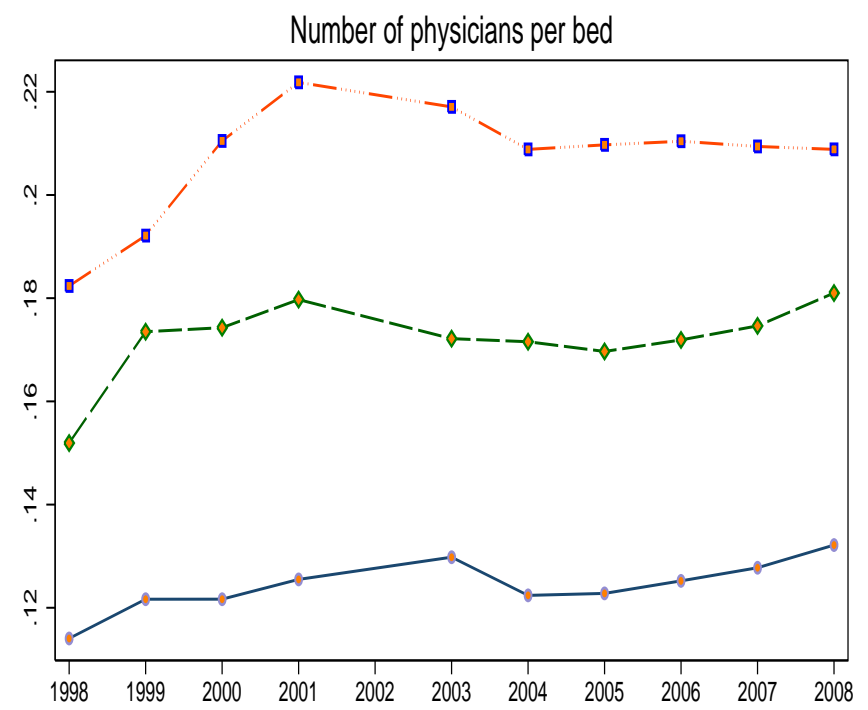

Table 4: 30-day Readmission Rates*

\begin{tabular}{lcccc}
\hline \multirow{2}{*}{ Readmission rates } & \multicolumn{2}{c}{ Not-For-Profit Hospitals } & \multicolumn{2}{c}{ For-Profit Hospitals } \\
\cline { 2 - 5 } & $\begin{array}{c}\text { Before } \\
\text { Global Budgets }\end{array}$ & $\begin{array}{c}\text { After } \\
\text { Global Budgets }\end{array}$ & $\begin{array}{c}\text { Before } \\
\text { Global Budgets }\end{array}$ & $\begin{array}{c}\text { After } \\
\text { Global Budgets }\end{array}$ \\
\hline \multirow{2}{*}{ AMI } & 0.070 & 0.054 & 0.124 & 0.099 \\
& $(0.25)$ & $(0.23)$ & $(0.33)$ & $(0.30)$ \\
& {$[16247]$} & {$[23500]$} & {$[3876]$} & {$[4837]$} \\
Ischemic & 0.090 & 0.078 & 0.105 & 0.101 \\
Heart Disease & $(0.29)$ & $(0.27)$ & $(0.31)$ & $(0.30)$ \\
& {$[86338]$} & {$[108161]$} & {$[24377]$} & {$[27630]$} \\
Hemorrhagic & 0.091 & 0.082 & 0.169 & 0.140 \\
Stroke & $(0.29)$ & $(0.27)$ & $(0.37)$ & $(0.35)$ \\
& {$[22759]$} & {$[27492]$} & {$[6221]$} & {$[6908]$} \\
Ischemic Stroke & 0.062 & 0.055 & 0.090 & 0.077 \\
& $(0.24)$ & $(0.23)$ & $(0.29)$ & $(0.27)$ \\
\hline
\end{tabular}

*Standard errors in parentheses, and number of observations in square brackets. 


\section{Data}

In this study, we use individual level data to investigate the impact of global budgeting on treatment intensity and outcomes of AMI, ischemic heart disease, hemorrhagic stroke, and ischemic stroke patients. Our data consist of claim records of Taiwan's National Health Insurance for the period 2000-2005, which covers the year when global budgeting for hospitals were launched, and two years prior to and three years after the launch of hospital global budgets. The daim records contain information on a hospitalized patient's dates of admission and discharge, and diagnoses. These records are maintained and distributed by Taiwan's National Health Research Institute (NHRI). The data we use contain every single record of AMI, ischemic heart disease, hemorrhagic stroke, and ischemic stroke during the period 2000-2005.

Since there is a unique record number for each incidence of admission, we can use this record number to identify the hospital that a patient is admitted to. This allows us to control for hospital characteristics, which may affect a patient's treatment intensity and outcomes. Information on hospital characteristics (including geographical location, accreditation, ownership, facilities, and medical staff manpower) come from the Registry for contracted medical facilities.

The NHI claim data also come with a unique identification number for each patient. This allows us to link a daim record to individuals in the Registry for beneficiaries. The Registry for beneficiaries contains basic characteristics of all individuals enrolling in NHI, e.g., age, gender, and changes in NHI status (i.e., withdrawal of insurance coverage). ${ }^{9}$

We use the daim records to construct four samples, each of which contains patients of one of the four diseases. In constructing a sample, we exclude patients who were

(a) hospitalized due to the same disease in the previous one year,

(b) admitted to a hospital, which treated less than 30 cases in the current year,

(c) hospitalized for the disease during the SARS epidemic (March-J uly, 2003),

(d) hospitalized during J uly of 2002 (the first month of hospital global budgets), and

(e) not discharged from hospital after admission.

\footnotetext{
${ }^{9} \mathrm{It}$ is through a patient's withdrawal of coverage that we identify her mortality status.
} 
Figure 7: Quantity of treatment received by AMI patients -Log of average number of points earned per patient

(a): All patients

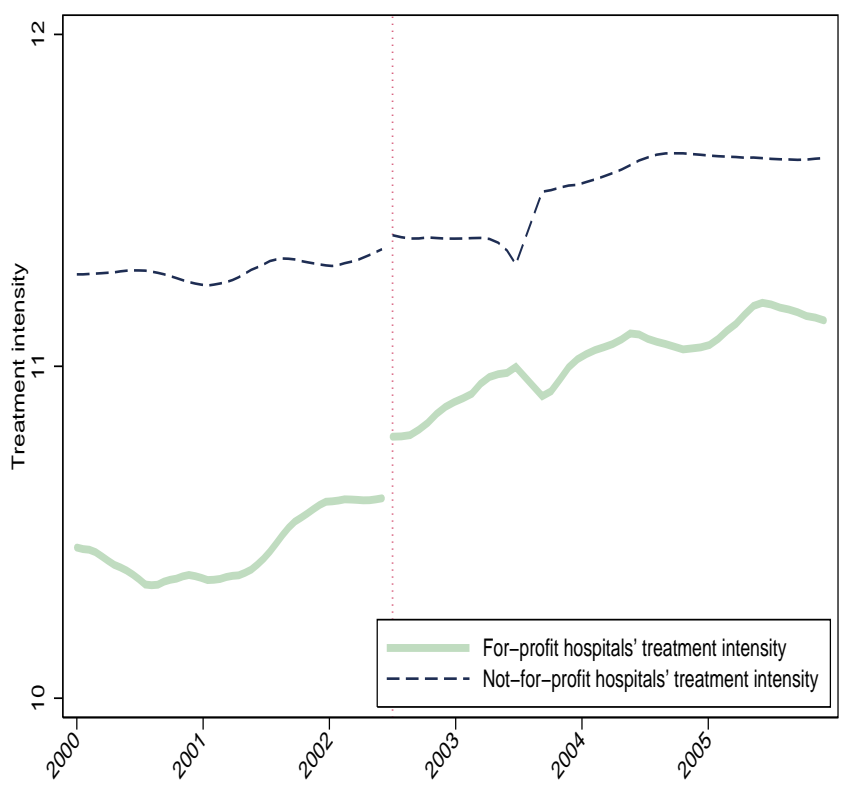

(c): Patients survived 30 days or more

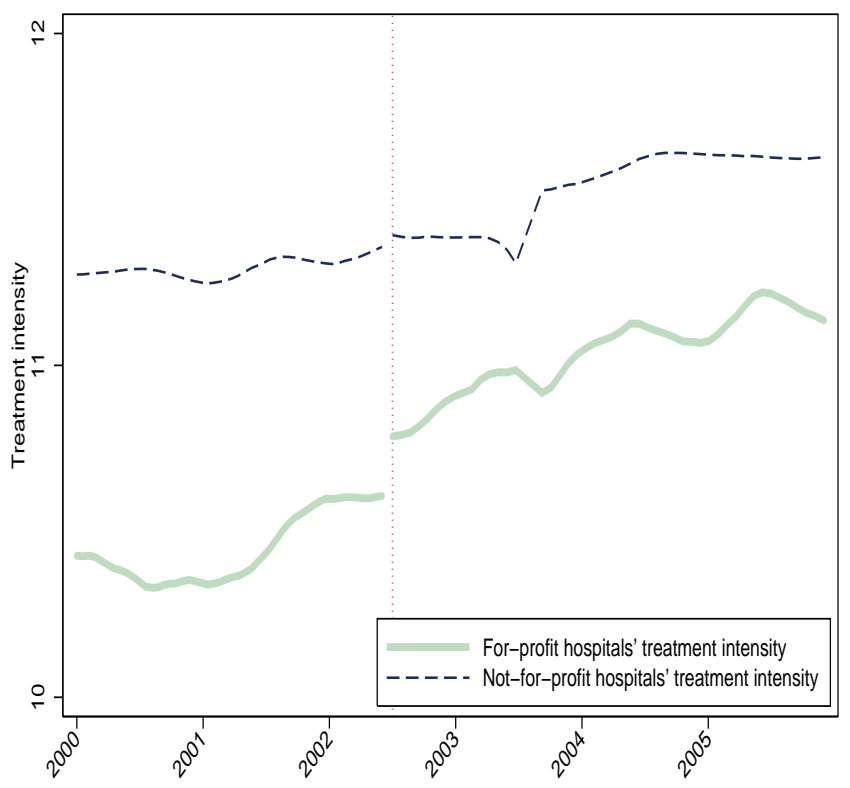

(b): Patients survived 7 days or more

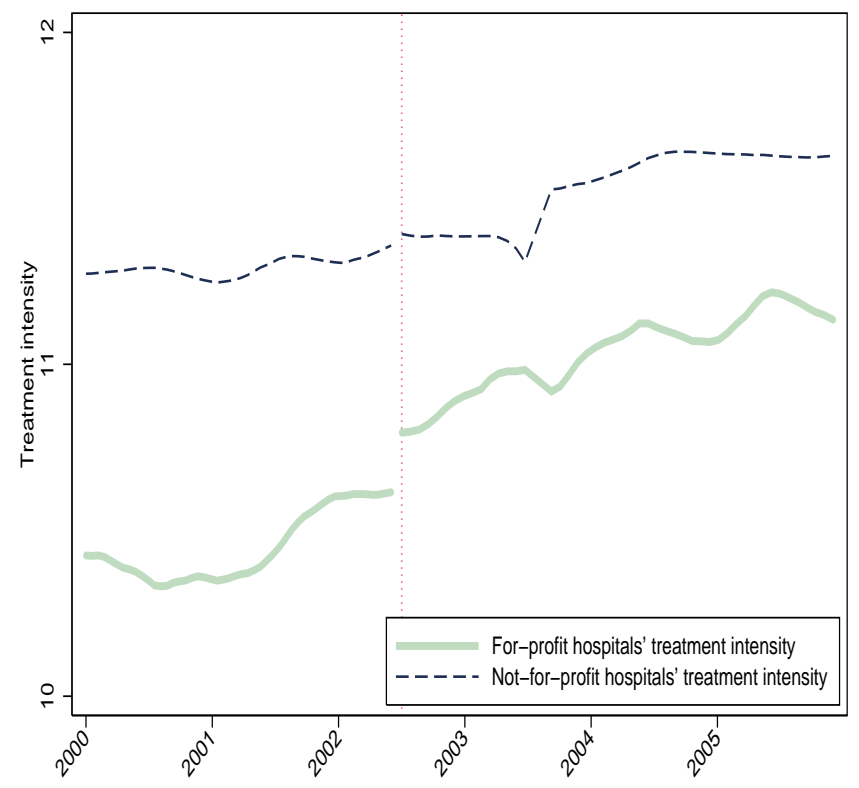

(d): Patients survived 90 days or more

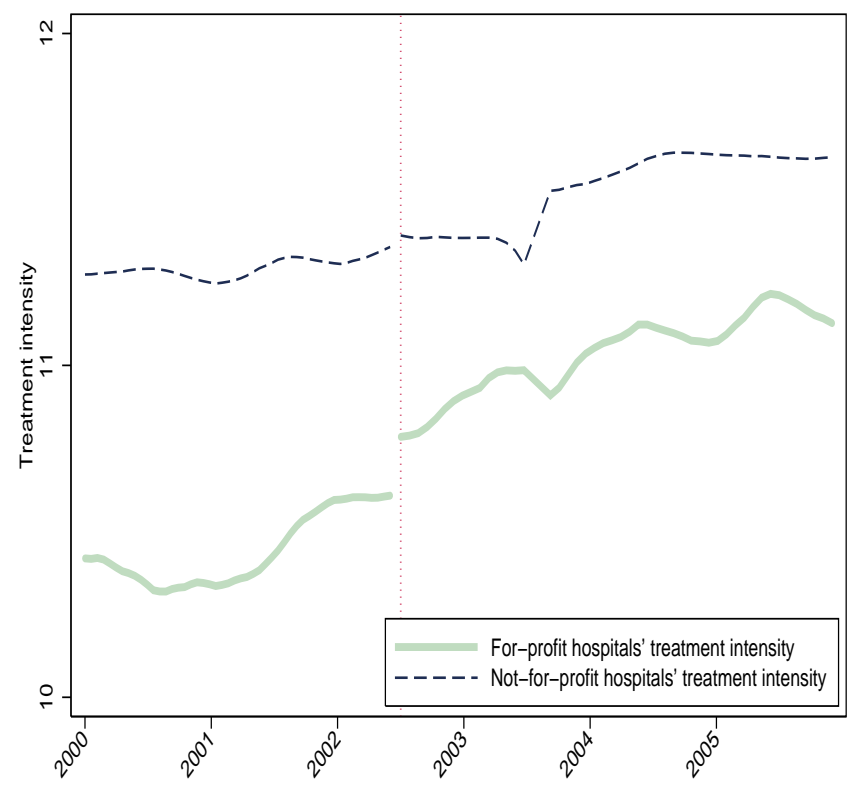

16 
Figure 8: Quantity of treatment received by ischemic heart disease patients-Log of average number of points earned per patient

(a): All patients

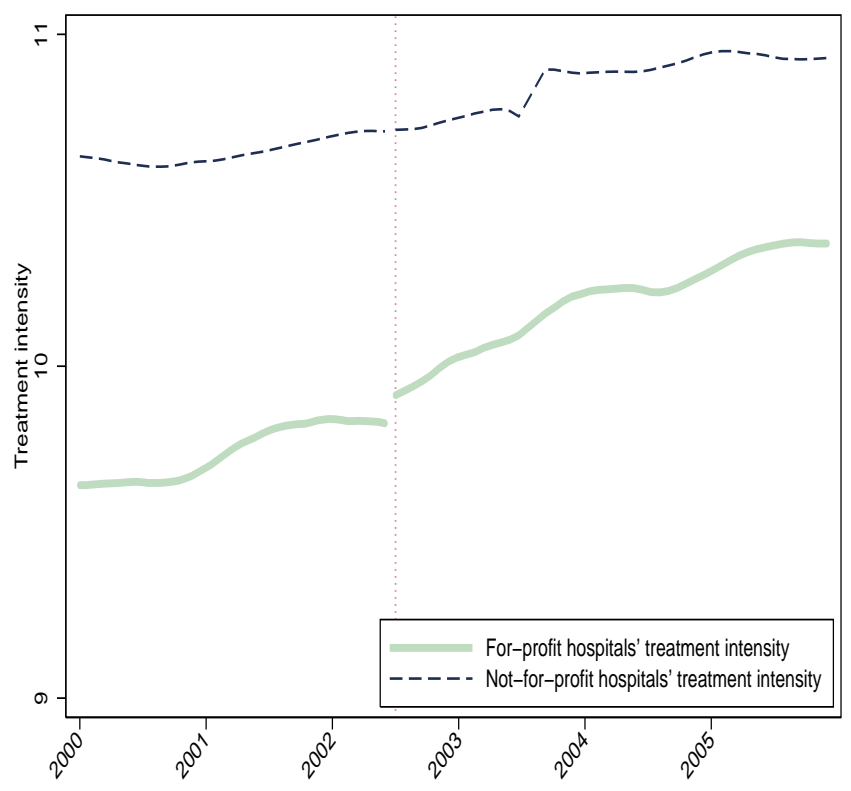

(c): Patients survived 30 days or more

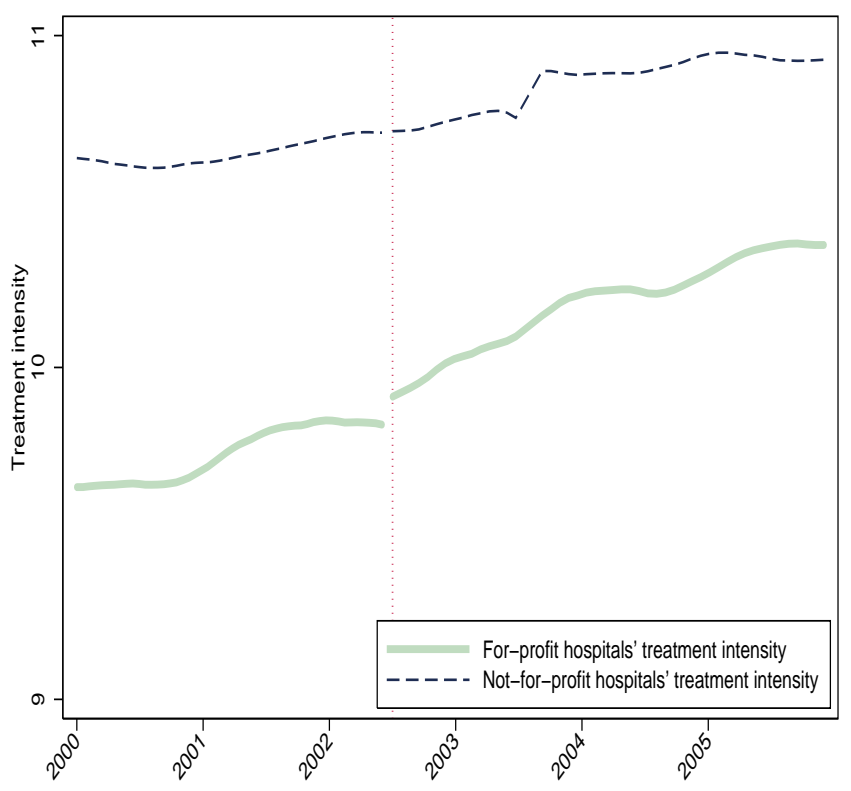

(b): Patients survived 7 days or more

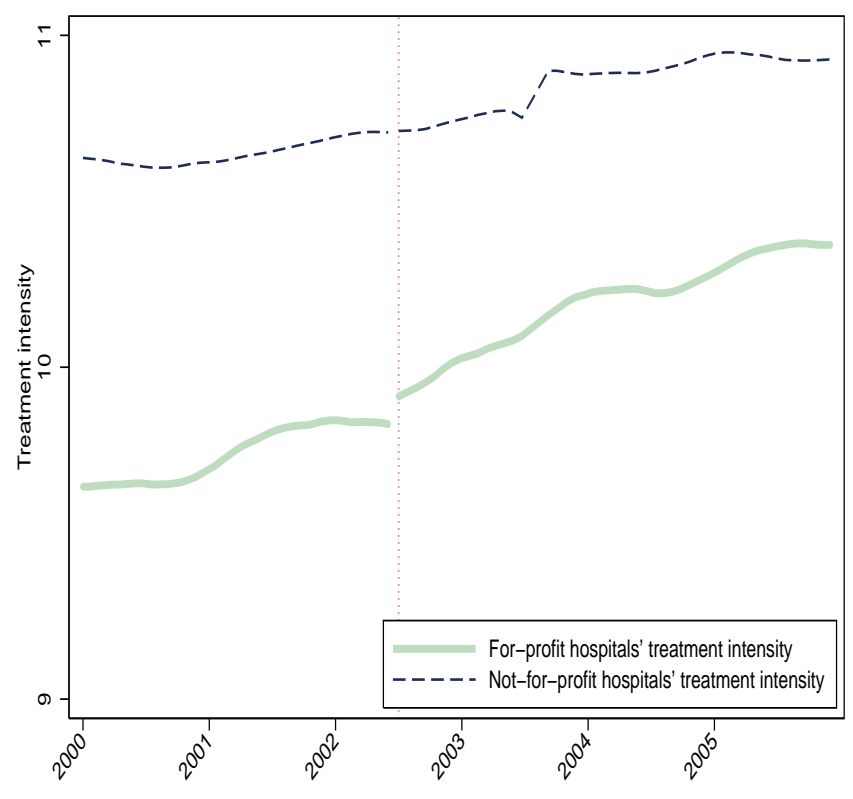

(d): Patients survived 90 days or more

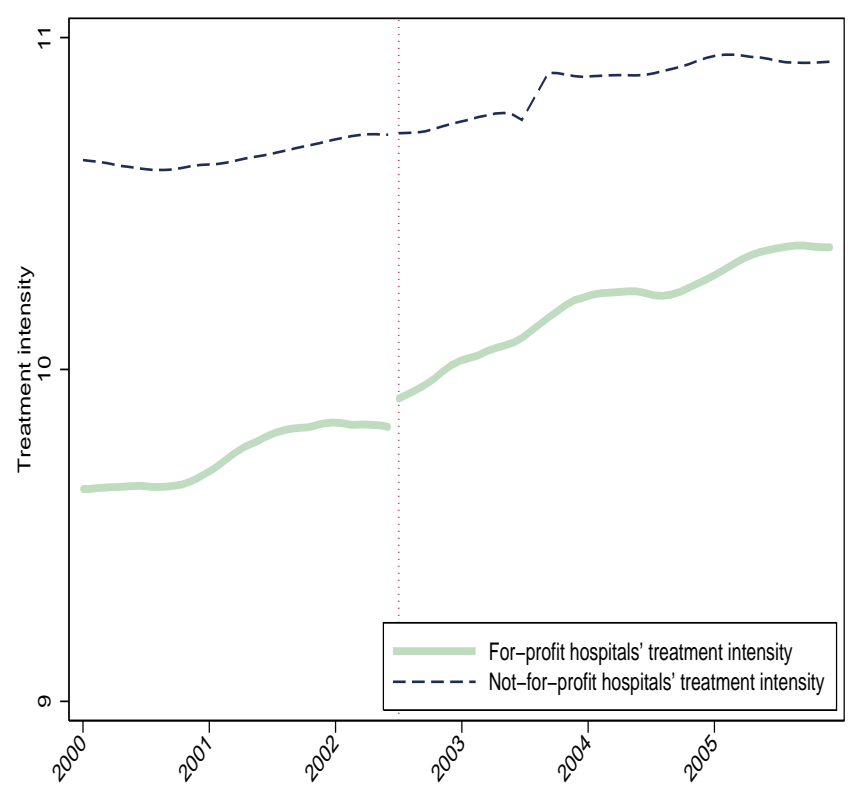


Figure 9: Quantity of treatment received by hemorrhagic stroke patients-Log of average number of points earned per patient

(a): All patients

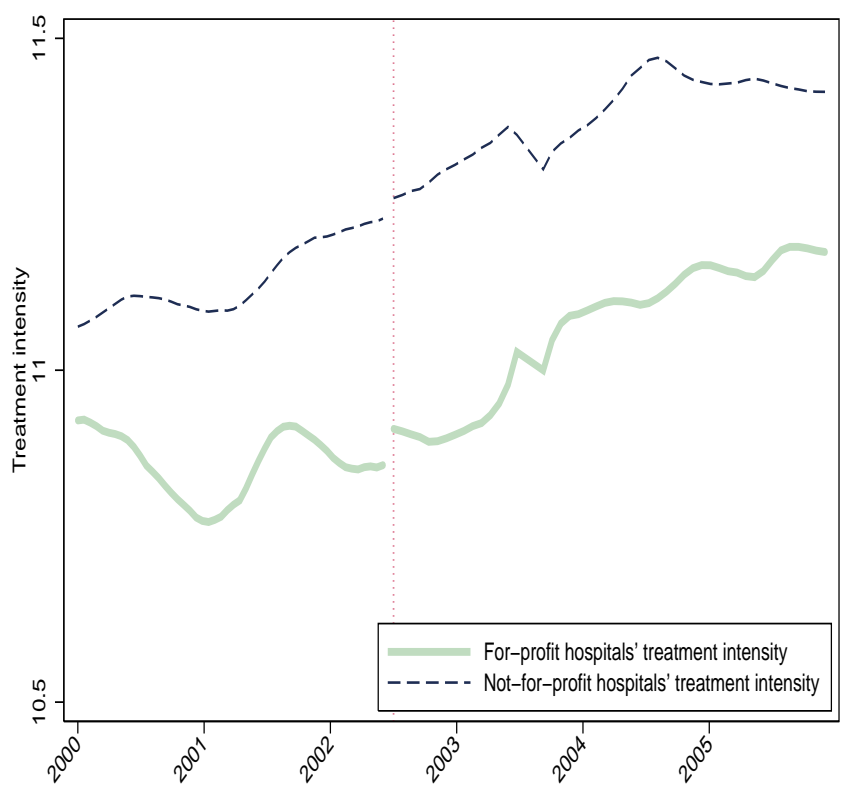

(c): Patients survived 30 days or more

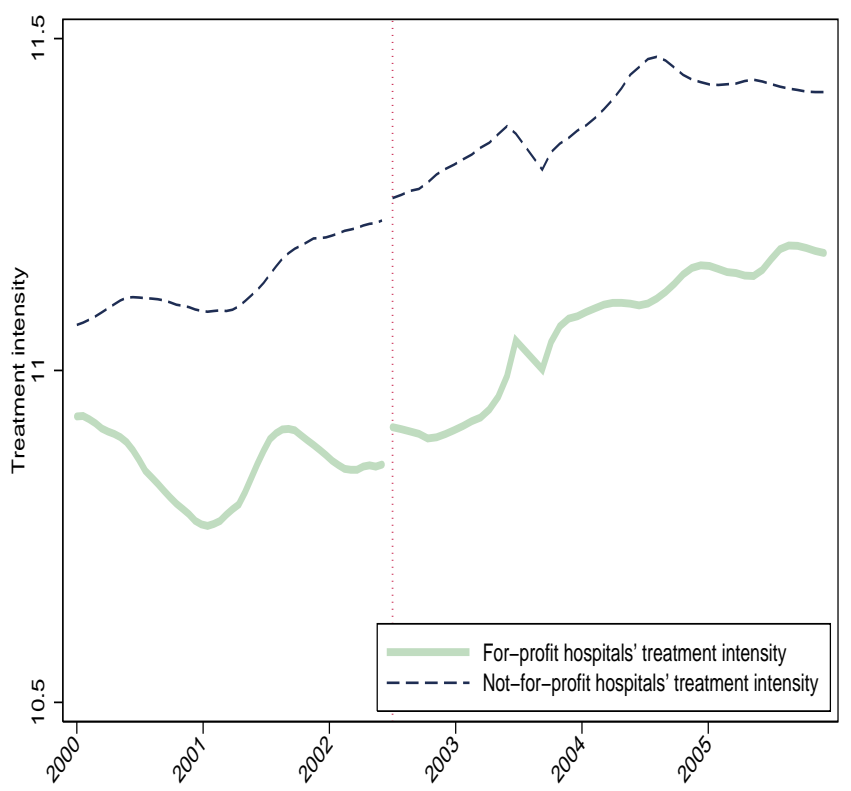

(b): Patients survived 7 days or more

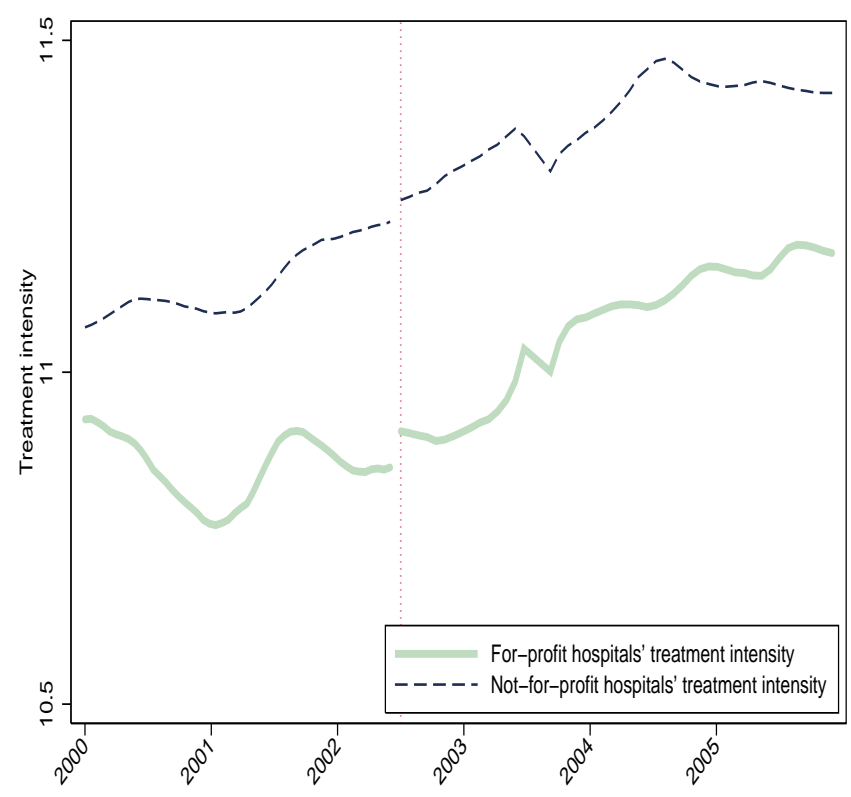

(d): Patients survived 90 days or more

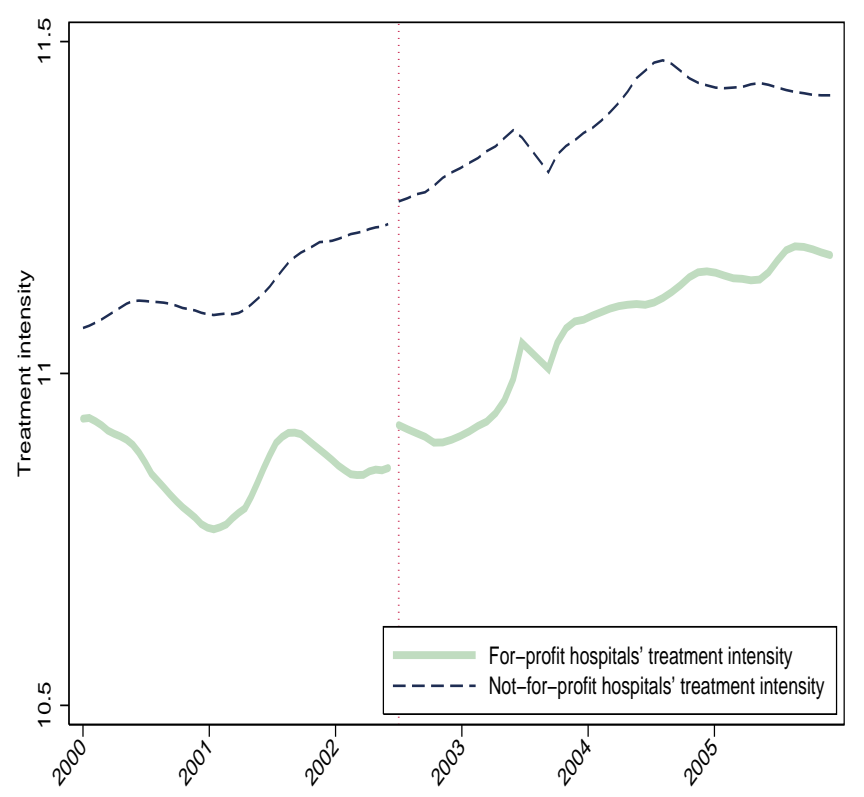


Figure 10: Quantity of treatment received by ischemic stroke patients_Log of average number of points earned per patient

(a): All patients

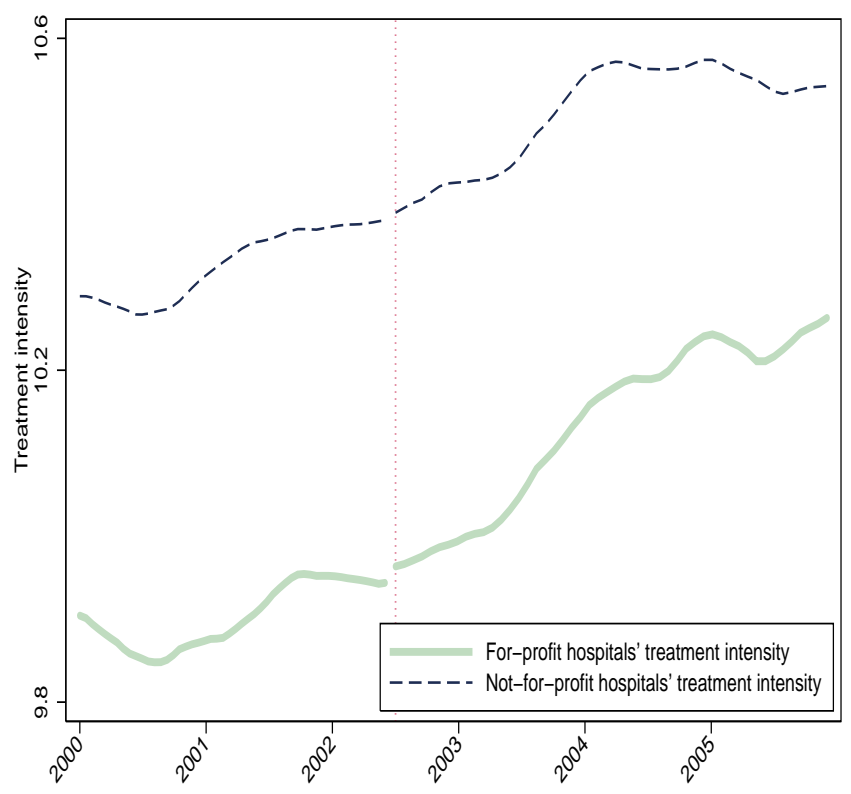

(c): Patients survived 30 days or more

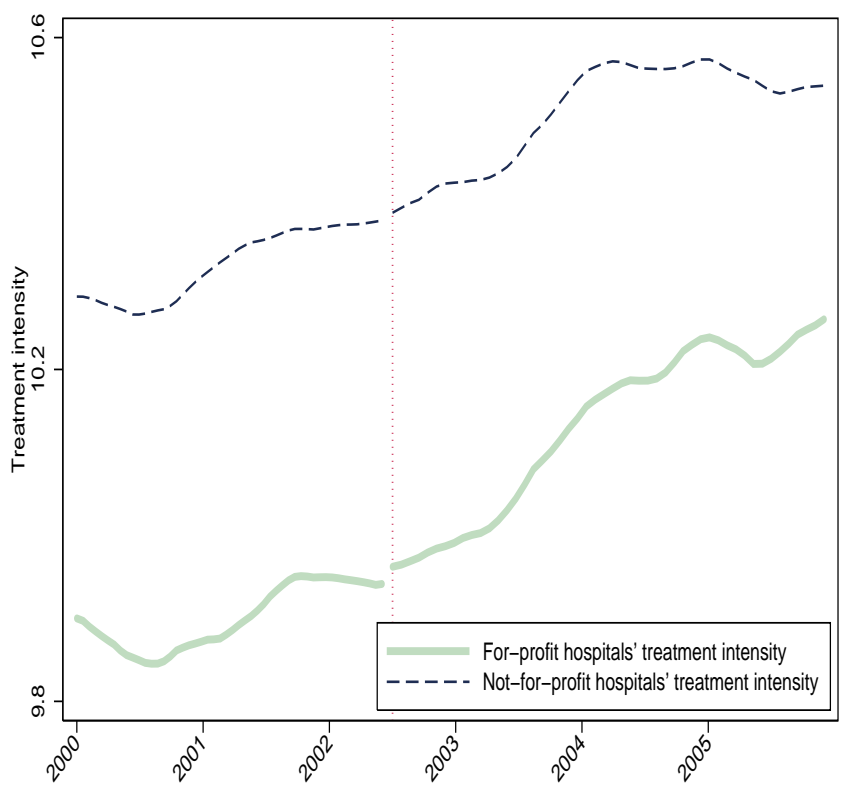

(b): Patients survived 7 days or more

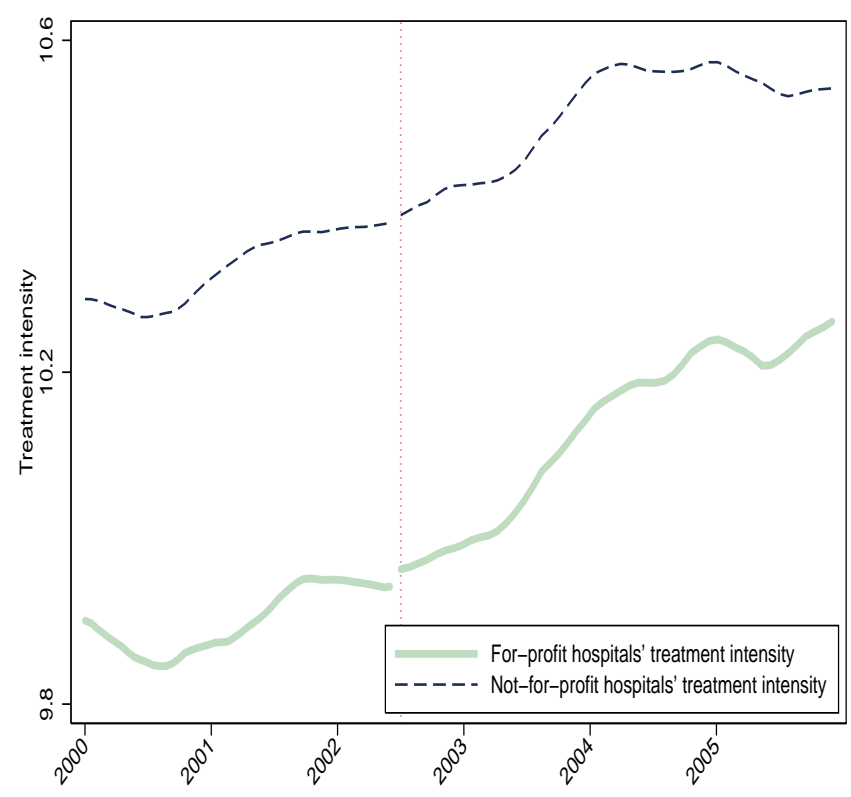

(d): Patients survived 90 days or more

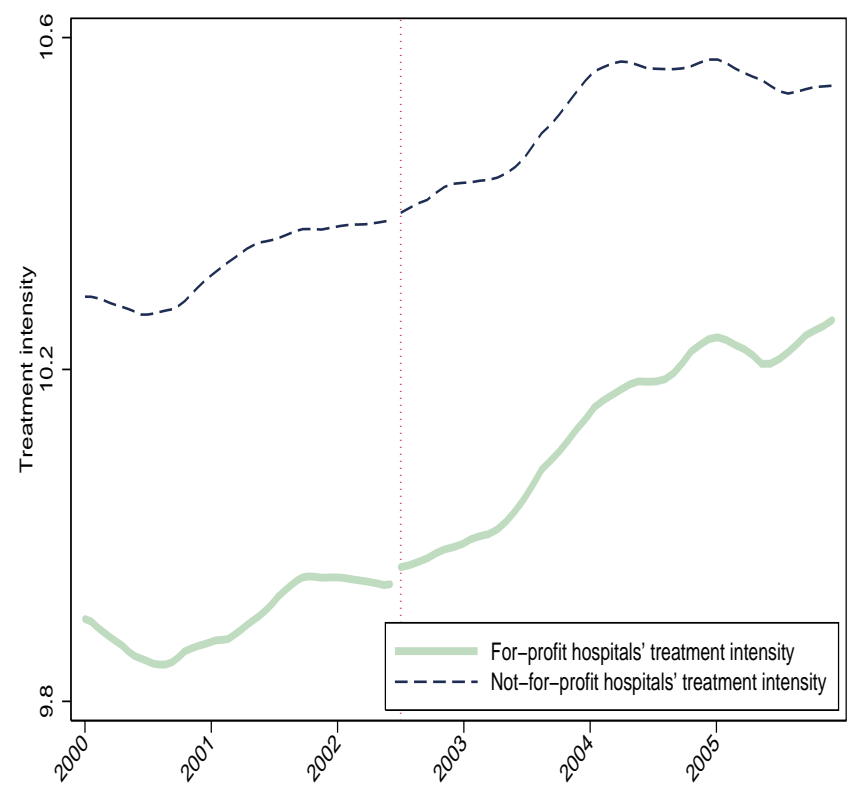


Figure 11: Average mortality and readmission rates of AMI patients

(a): 30-day readmission rate

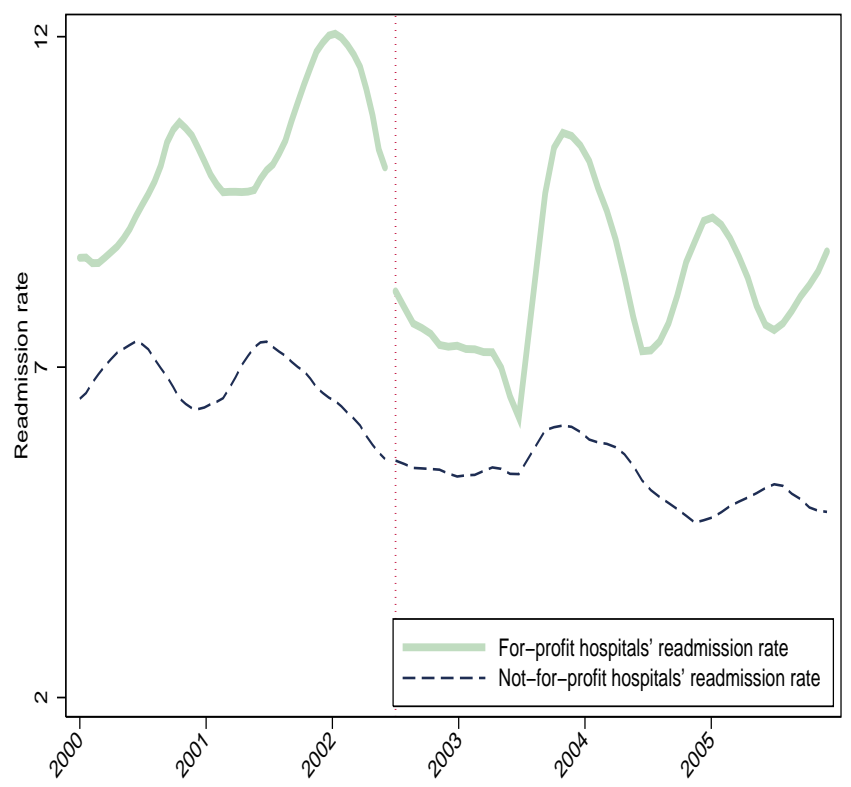

(c): 30-day mortality rate

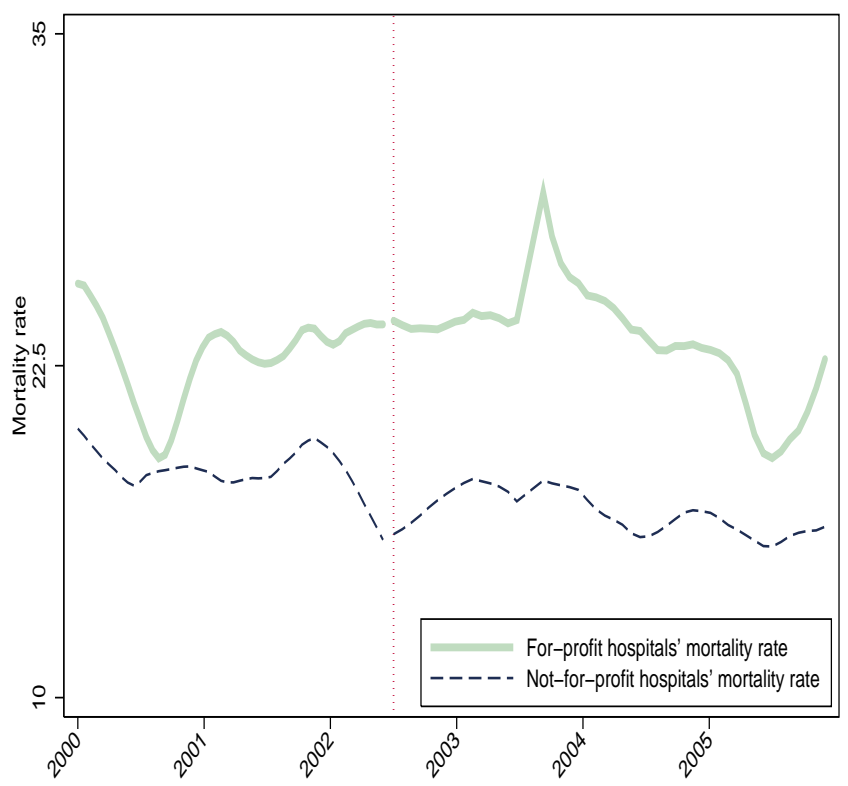

(b): 7-day mortality rate

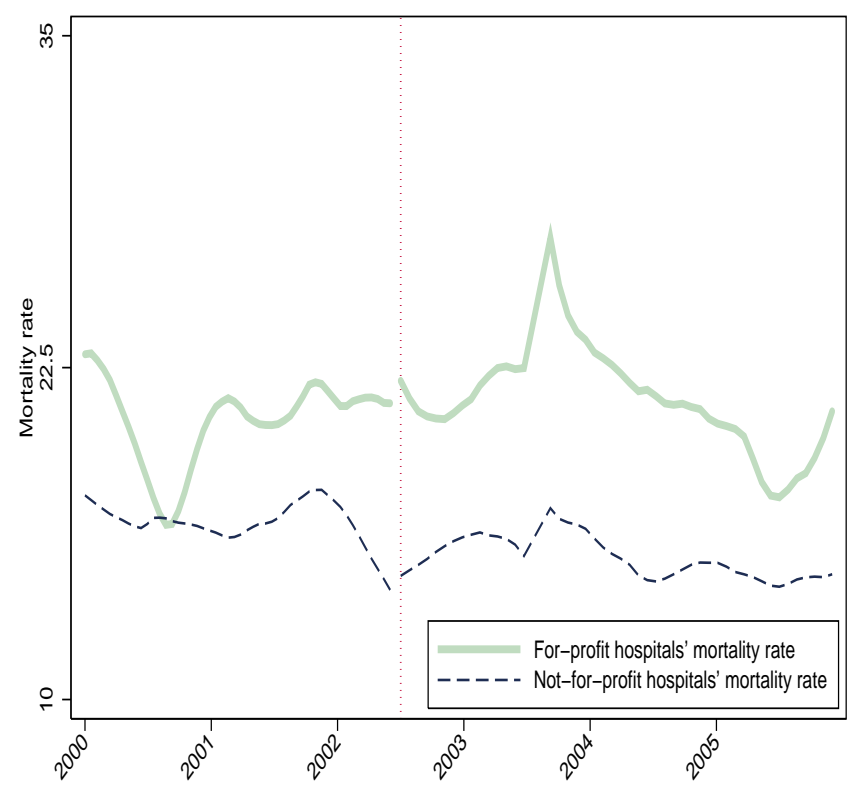

(d): 90-day mortality rate

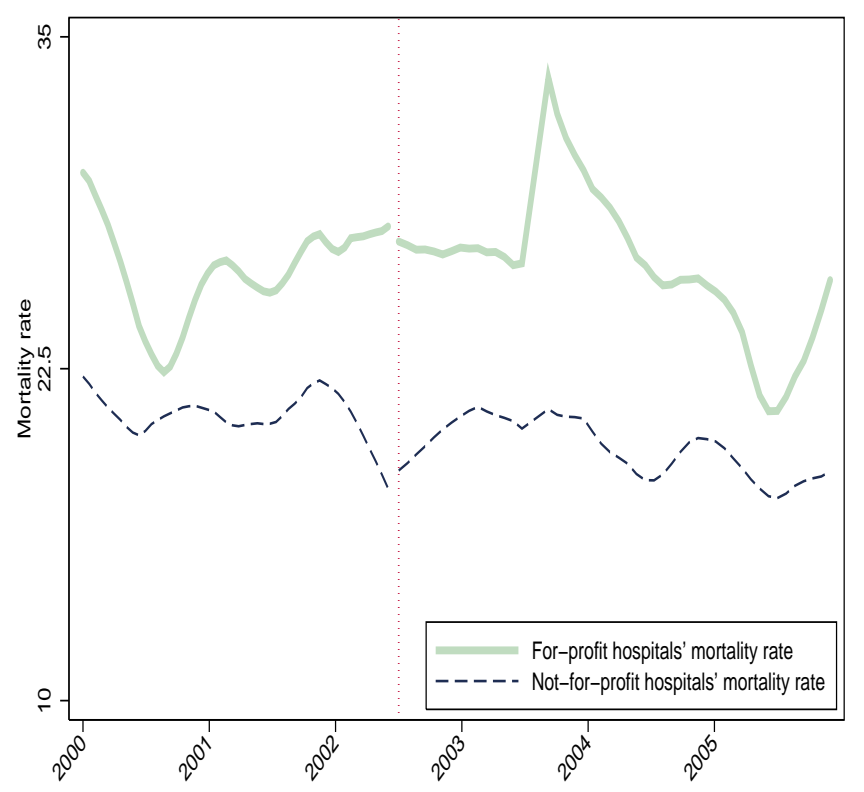


Figure 12: Average mortality and readmission rates of ischemic heart disease patients

(a): 30-day readmission rate

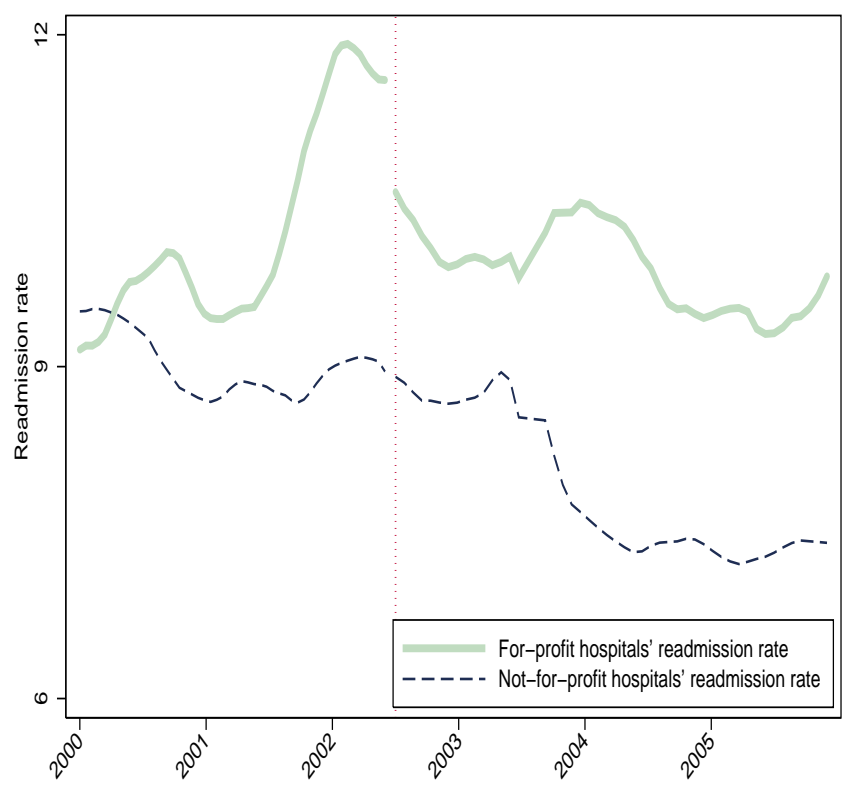

(c): 30-day mortality rate

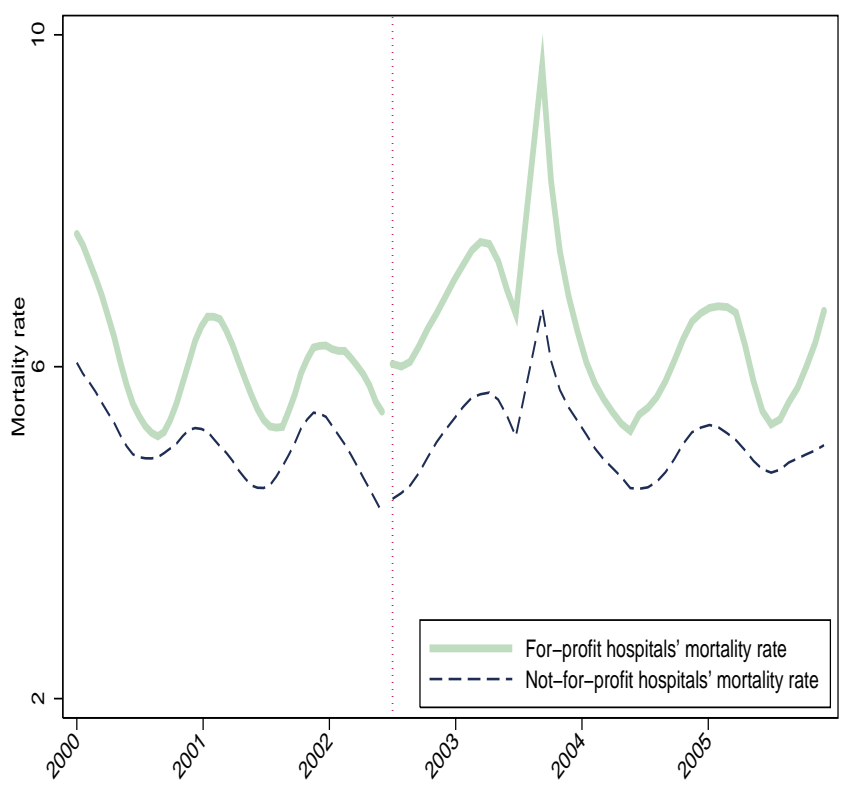

(b): 7-day mortality rate

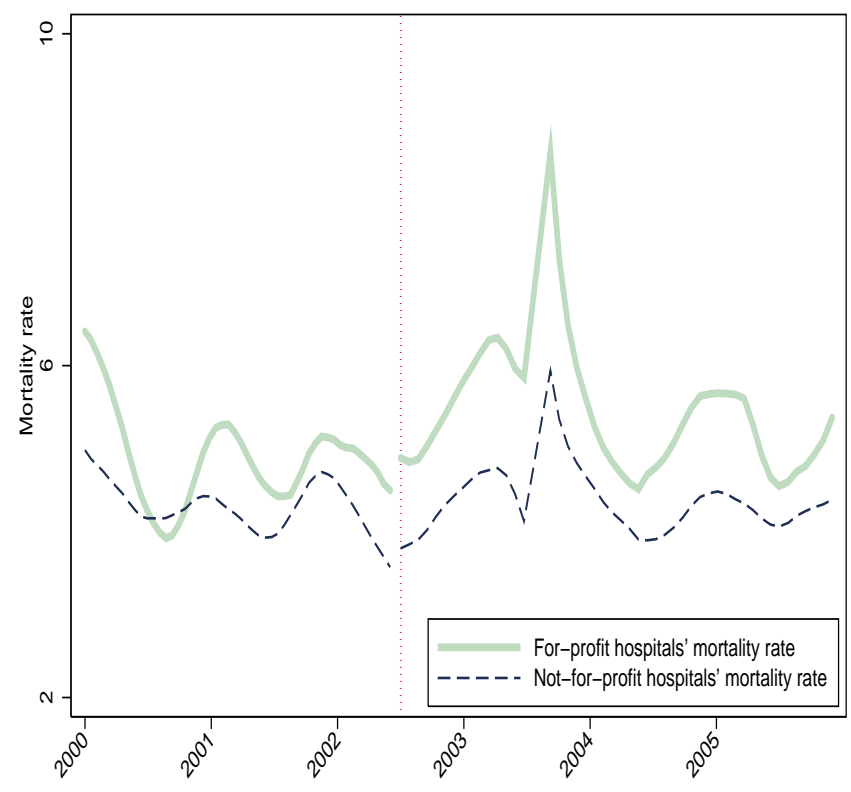

(d): 90-day mortality rate

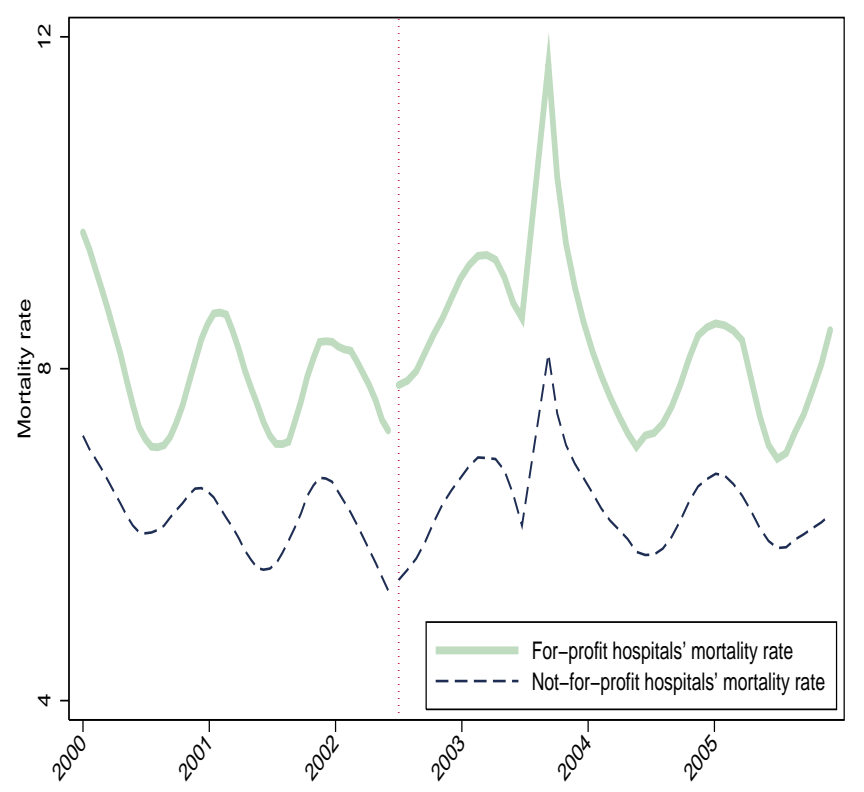


Figure 13: Average mortality and readmission rates of hemorrhagic stroke patients

(a): 30-day readmission rate

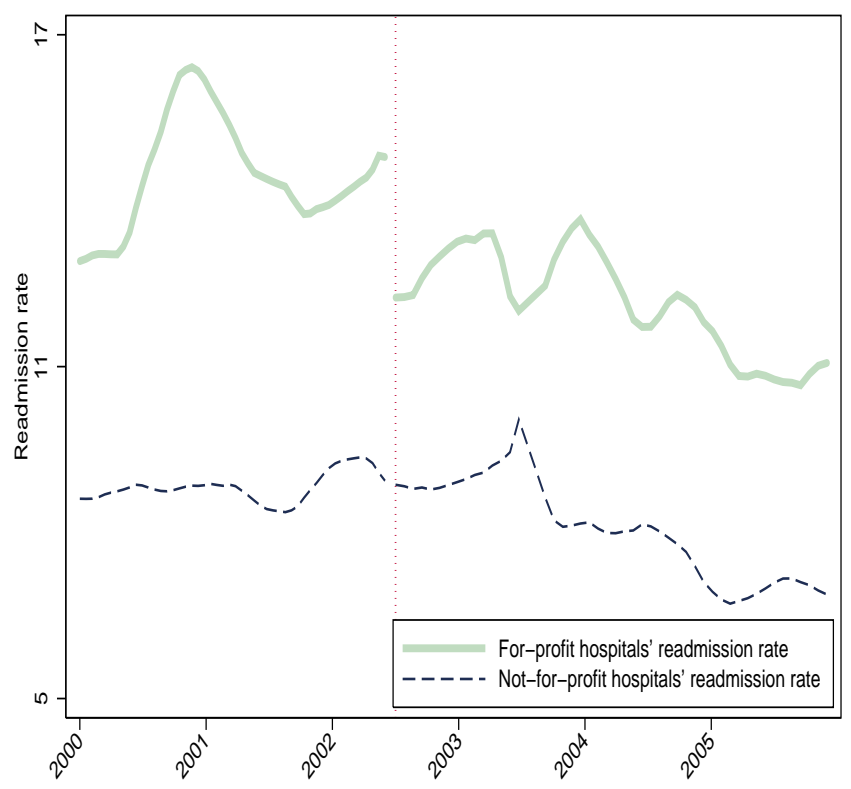

(c): 30-day mortality rate

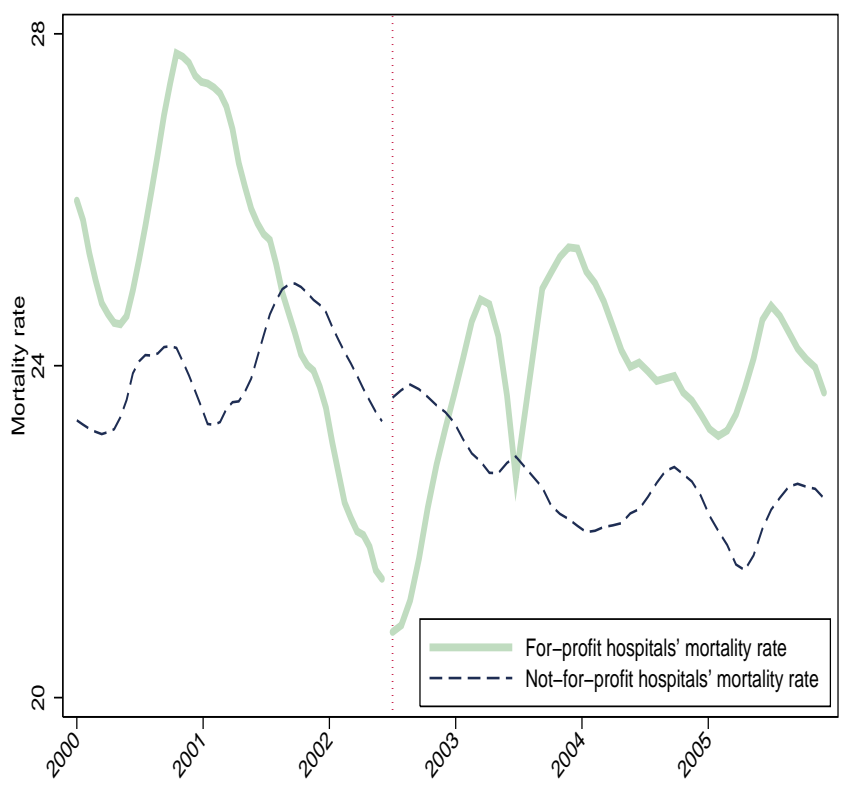

(b): 7-day mortality rate

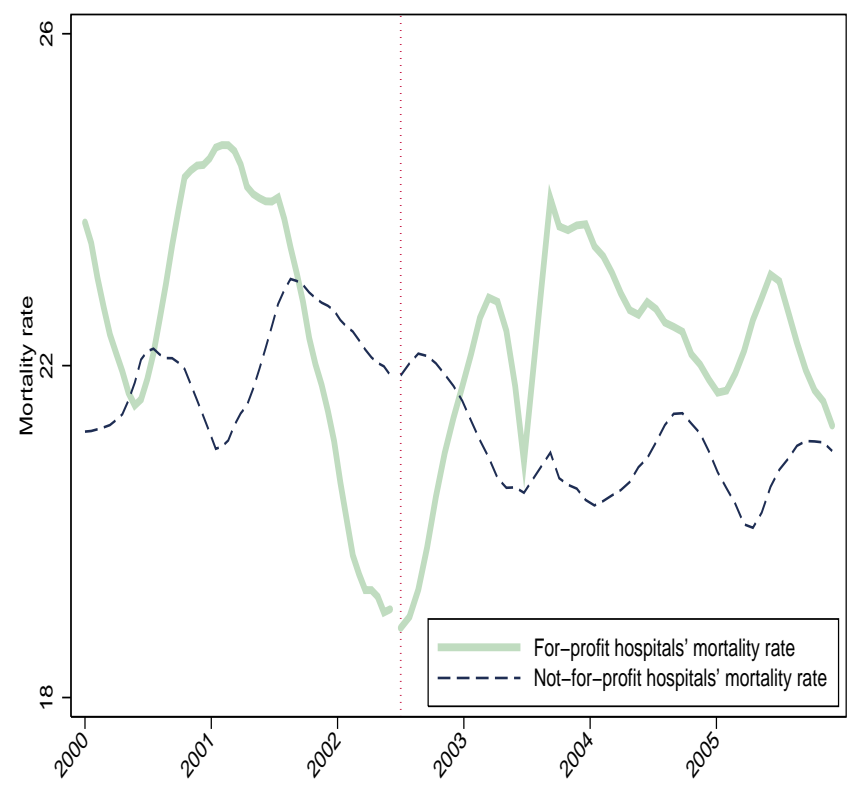

(d): 90-day mortality rate

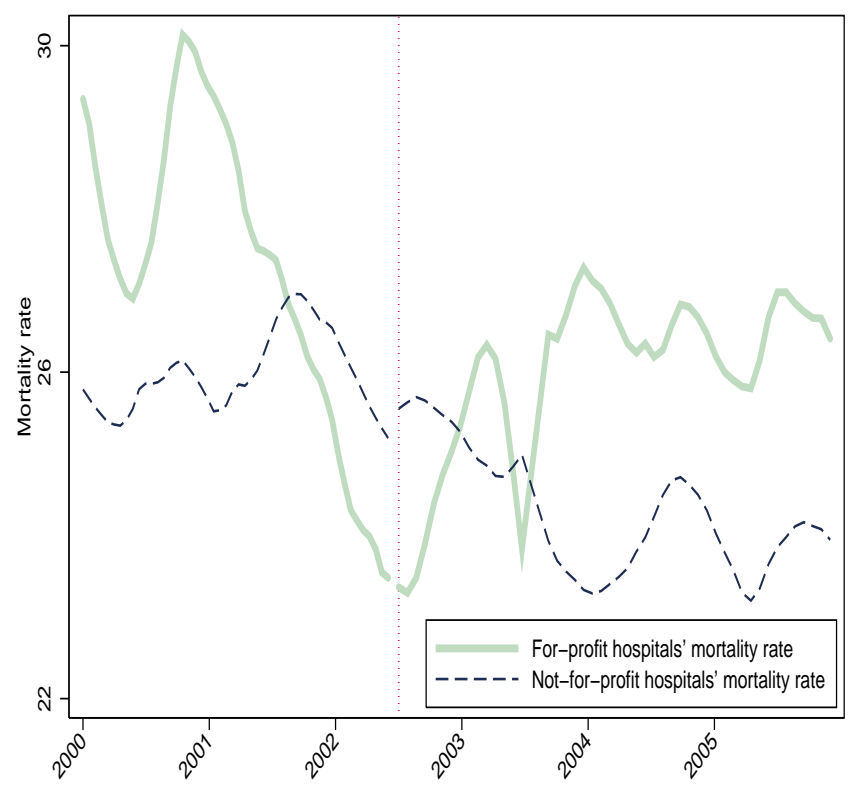


Figure 14: Average mortality and readmission rates of ischemic stroke patients

(a): 30-day readmission rate

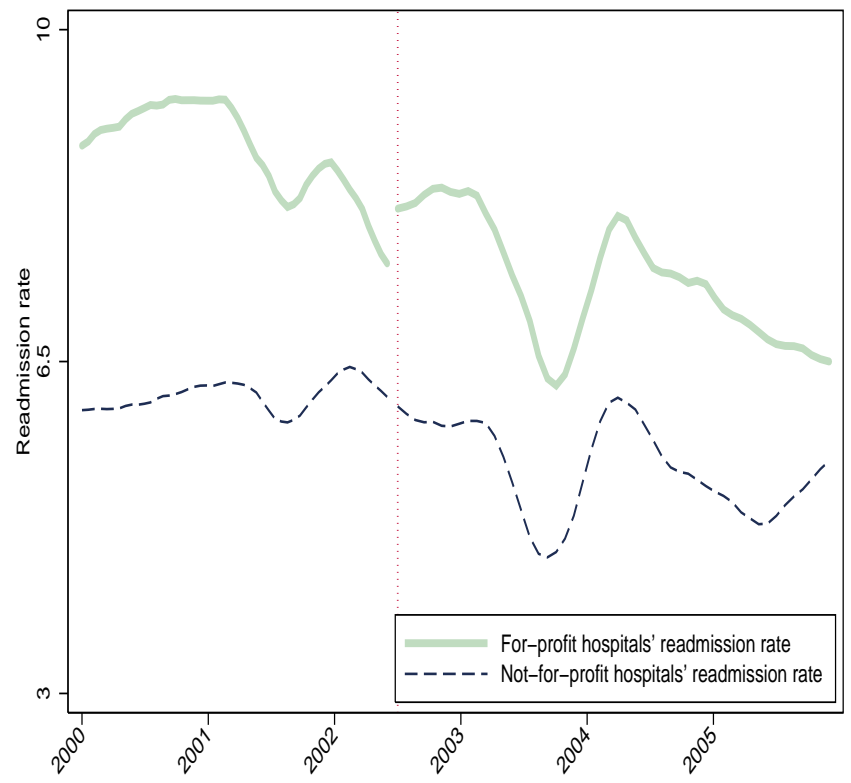

(c): 30-day mortality rate

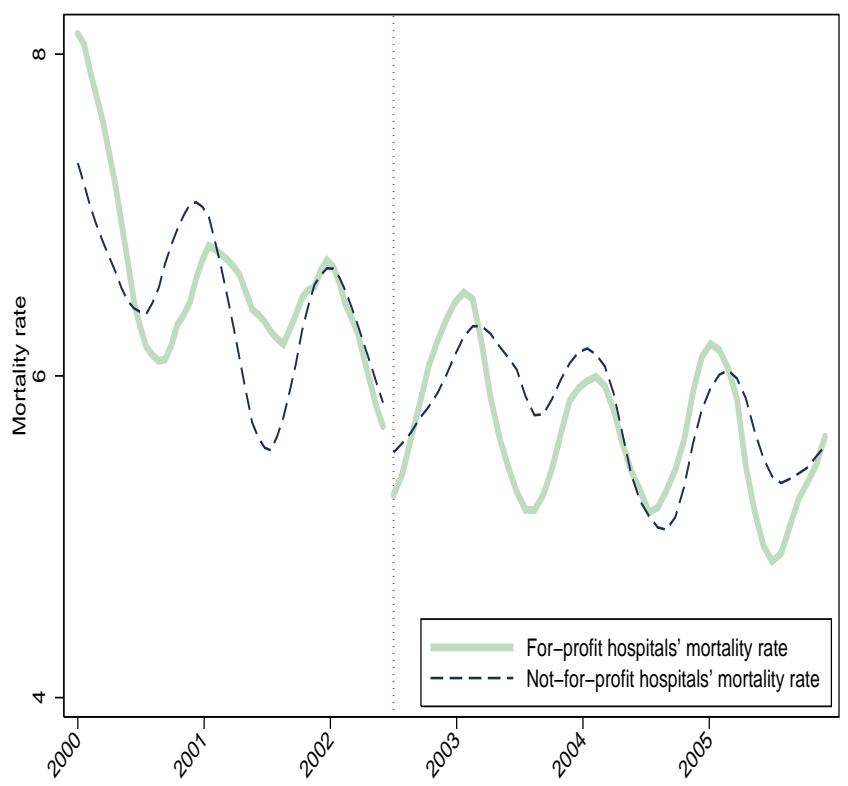

(b): 7-day mortality rate

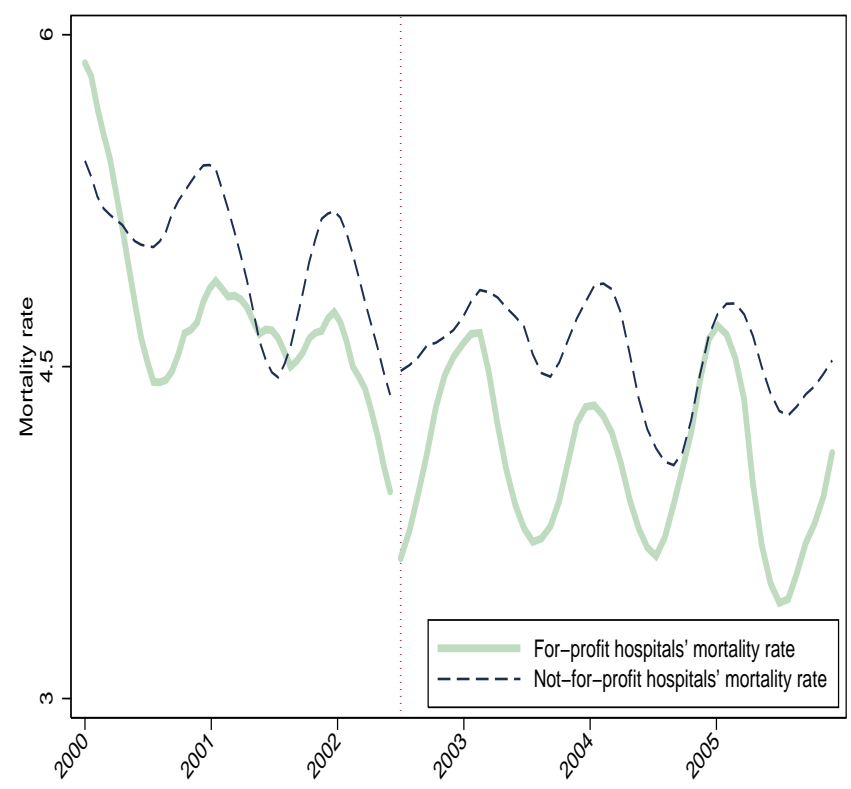

(d): 90-day mortality rate

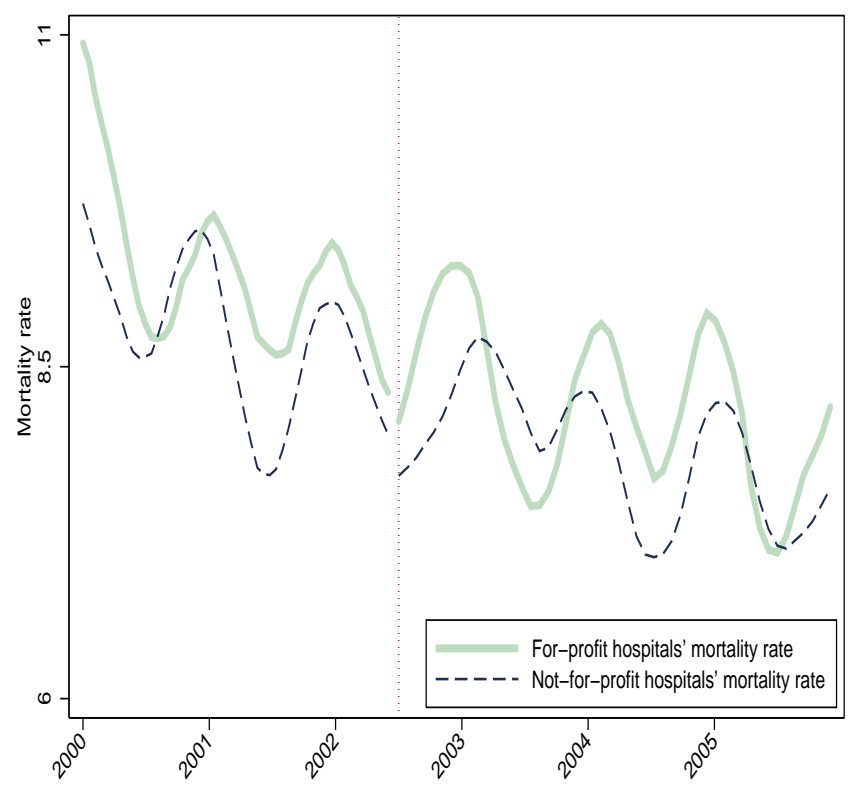


These criteria for sample sel ection are to exclude non-typical cases. The deletion of patients having hospitalized for one of the four diseases during the previous year from our sample of that disease is to make sure their treatment intensity and outcomes are not confounded by previous treatments. Hospitals treating less than 30 cases in a given year may not be comparable with other hospitals. Sample selection criterion (c) is imposed because during the SARS epidemic the point values were raised by Bureau of National Health Insurance to encourage hospitals to supply sufficient services. The SARS pandemic may also have discouraged some patients to seek medical treatment. The last sample sel ection criterion (e) suggests that we only examine post-discharge treatment outcomes. Discharge of a patient by a hospital implies that necessary treatments for the patient is considered complete by the hospital. Thus, to a large extent the incidence of mortality or readmission of such a patient should reflect the effect of treatment rather than severity of the patient's condition.

There are 40,444, 232,157, 49,373, and 155,884 patients, respectively, in our AMI, ischemic heart diseases, hemorrhagic stroke, and ischemic stroke samples. In our empirical analysis, we examine the impact of global budgeting on a patient's treatment intensity and outcomes, while controlling for her demographic characteristics and comorbidity conditions. We use the number of points awarded by the Bureau of National Health Insurance to a hospital for treating a particular patient as a proxy for the intensity of treatments. We measure a patent's treatment outcomes based on the incidences of

(1) readmission within 30 days after discharge,

(2) mortality within 7 days after discharge,

(3) mortality within 30 days after discharge,

(4) mortality within 90 days after discharge.

For the mortality measures, we exclude patients who transferred from one hospital to another. This is because in such cases it is difficult to identify the hospital which is associated with the outcomes of a patient. There are 3,824, 32,271, 4,133 and 4,823 such cases, respectively, in the AMI, ischemic heart diseases, hemorrhagic stroke, and ischemic stroke samples. To define the variable on readmission, we drop patients who died within 30 days of discharge. There are 1,071, 3,440, 2,317, and 1,661 such cases, respectively, in the AMI, ischemic heart disease, hemorrhagic stroke, and ischemic stroke samples. 
The average number of points earned by hospitals for treating each inpatient is displayed in Table 3. We see that patients in not-for-profit hospitals received higher intensity of treatment. Moreover, there was a large increase in the average number of points earned by both for-profit and not-for-profit hospitals after the adoption of hospital global budgets. This implies that there is an increase in treatment intensity. To see whether this increase is part of the time trend, we look at Figures 7 to 10, which display the smoothed curves of the daily averages of treatment intensity for for-profit and not-for-profit hospitals. We apply the method of Iocal polynomial (see Fan and Gijbels, 1996) to produce these smoothed curves. These smoothed curves show that there is a jump in treatment intensity surrounding the introduction of global budgets for AMI, ischemic heart disease, and (to a less extent) ischemic stroke patients admitted to for-profit hospitals. However, for not-for-profit hospitals the increase seems to follow a time trend and there is no clear jump in treatment intensity surrounding the adoption of global budgets, with the exception of hemorrhagic stroke patients.

The average readmission and mortality rates for different types of hospitals during 2000-2005 are reported in Tables 4 and 5, which show that the mortality and readmission rates for patients admitted to not-for-profit hospitals were lower, and there was an improvement in the treatment outcomes of patients admitted to both for-profit and notfor-profit hospitals. The daily average of the readmission and mortality rates smoothed by the method of local polynomial are plotted in Figures 11-14. A salient feature of the pattern of readmission and mortality rates is that, there is not clear time trend. In addition, for-profit hospitals' readmission and mortality rates are more volatile their not-for-profit counterparts.

Moreover, there was a decrease in readmission and mortality rates for both for-profit and not-for-profit hospitals after the launch of hospital gl obal budgets for patients suffering from ischemic strokes only. However, there does not seem to exist a jump or sharp discontinuity in the readmission and mortality rates, except for the readmission rates of AMI, ischemic heart, hemorrhagic stroke patients, in for-profit hospitals. This seems to imply that despite a surge in treatment intensity, there is not much improvement in treatment outcomes. 
In our empirical analysis, we control for certain regional and patient level characteristics which may affect the outcomes of treatment. We control for the degree of hospital market competitiveness of the medical region that a hospital locates via the Herfindahl-Hirschman index $(\mathrm{HHI})$. In terms of patient level demographic characteristics, only the gender and age of the patients are available in the data. To measure a patient's comorbidity conditions we construct the Charlson Comorbidity Index. The sample descriptive statistics of these variables are displayed in Table 6 . The descriptive statistics in Table 6 suggest that forprofit hospitals are usually in more competitive markets, and their patients are slightly older, more likely to be female, and high $\mathrm{CCl}$ score (i.e., in a more severe health condition). However, these differences between for-profit and not-for-profit hospitals are not large.

\section{Empirical Strategy and Results}

To examine the effect of global budgeting on treatment intensity and treatment outcomes of patients hospitalized because of AMI, ischemic heart disease, hemorrhagic stroke, or ischemic stroke, we estimate the following linear probability model.

$$
\mathrm{y}_{\text {hid }}=\alpha \mathrm{GB}_{\mathrm{d}}+\tau_{1} \text { trend }_{\mathrm{d}}+\tau_{2} \operatorname{trend}_{\mathrm{d}}^{2}+\boldsymbol{\beta} \mathbf{x}_{\mathrm{hid}}+\eta_{\mathrm{h}}+\epsilon_{\mathrm{hid}},
$$

where $\mathrm{d}$ index calendar dates, $\mathrm{h}$ index the hospital where patient $\mathrm{i}$ is admitted, $\mathrm{y}_{\text {hid }}$ is an outcome of interest (i.e., treatment intensity or outcomes of patients suffering a certain disease), $\mathrm{GB}_{d}$ is a gl obal budgeting indicator, i.e., $\mathrm{GB}_{d}=1$ if $d \geq J$ uly 1,2002 , trend $d$ is a time trend at the monthly frequency, $\mathbf{x}_{\text {hid }}$ is a vector containing patient characteristics (i.e., $\mathrm{CCl}$ scores, age, gender), medical region $\mathrm{HHI}$, and month dummies, $\eta_{\mathrm{h}}$ is a hospital fixed effect, and $\epsilon_{\text {hid }}$ is a residual. We use $\eta_{\mathrm{h}}$ to control for time-invariant hospital heterogeneity. Since the characteristics of hospitals do not change very much over time, $\eta_{\mathrm{h}}$ should be sufficient in capturing hospital heterogeneity.

The specification in (1) follows a regression discontinuity design with a parametric specification. Under this specification, we identify the effect of global budgeting by detecting a discrete jump or sharp discontinuity in the outcome yhid surrounding the implementation of gl obal budgeting. This is captured by the coefficient $\alpha$. The estimation of (1) is via the linear 
regressions with hospital fixed effects. The computation of standard errors of the coefficient estimates takes into account clustering at the hospital level. Nonparametric methods for regression discontinuity designs have been proposed (see Lee and Lemieux, 2010). The reason why we adopt a parametric specification in the current paper is that we want to control for hospital fixed effects and some other patient characteristics, which are nonnegl igible determinants of treatment intensity and outcomes. This is infeasible if we use a nonparametric method in terms of computational time. Moreover, the use of a nonparametric method involve the issue of bandwidth choice, which is not trivial.

For treatment intensity, the dependent variable is the log of the number of points that a hospital earned from treating a patient. We estimate (1) for patients surviving a certain number of days after being admitted to a hospital. With respect to treatment outcomes, for each disease, we look at four outcomes for a patient, namely, mortality within 7, 30, and 90 days after discharge, and readmission within 30 days after discharge. In the model we allow yhid to follow a quadratic time trend, i.e., $\tau_{1}$ trend $_{d}+\tau_{2}$ trend $_{d}^{2}$.

\section{Treatment Intensity}

The estimation results are reported in Tables 7-8. The results pertaining to treatment intensity are in Table 7. The coefficient estimates of the impact of the launching of global budgets (estimates of $\alpha$ ) in column (2), (4), (6), and (8) of Table 7 suggest that there is a substantial increase in the treatment intensity for patients admitted to for-profit hospitals. For example, for AMI and ischemic heart disease patients regardless of the length of survival, the quantity of treatment increased by $17.9 \%$ and $12.2 \%$. For hemorrhagic stroke patients, the coefficient estimates are statistically insignificant for all patients regardless of survival length. However, for patients surviving more than 7, 30, and 90 days, their treatment intensity increased by more than ten percent, and these increases are statistically significant. There is not much increase in ischemic stroke patients' treatment intensity. The coefficient estimates indicate that the increase was about three percent, but these estimates are statistically insignificant.

The coefficient estimates for patients admitted to not-for-profit hospitals are presented 
in columns (1), (3), (5), and (7) of Tables 7. The treatment intensity of patients admitted to not-for-profit hospitals did not increase very much. For AMI patients regardless of length of survival, they received $7.2 \%$ more treatment. However, for patients suffering from other diseases, their increases were negligible according the coefficient estimates, which are statistically insignificant.

In summary, the results pertaining to treatment intensity suggest that the launch of hospital global budgets in Taiwan did not lead to an obvious increase in treatment intensity received by patients admitted to not-for-profit hospitals. On the contrary, there is a discernible increase in treatment intensity for patients admitted to for-profit hospitals. The reaction for-profit hospitals' treatment intensity to global budgets are consistent with the predictions of Fan et al. (1998) and Benstetter and Wambach (2006). The sluggish response of not-for-profit hospitals' treatment intensity to global budget is likely to be due to their lack of profit motive.

\section{Treatment Outcomes}

The estimation results pertaining to the impact of gl obal budgets on treatment outcomes of patients admitted to not-for-profit and for-profit hospitals are presented in Table 8. According to columns (2), (4), (6), and (8) of Table 8, the coefficient estimates of $\alpha$ suggest that global budgets did not have very much impact on the treatment outcomes of patients admitted to for-profit hospitals. For AMI patients, see column (2) of Table 8, global budget reduced the rate of readmission within 30 days of discharge by 5.506 percentage points, which is marginally significant. For outcomes pertaining to mortality, the coefficient estimates are statistically insignificant, implying a lack of effect of gl obal budgets.

For AMI patients admitted to not-for-profit hospitals, there were no significant changes in treatment outcomes. According to column (1) of Table 8, the coefficient estimates of $\alpha$ are small in magnitude and statistically insignificant.

The estimate results pertaining to ischemic heart disease patients are displayed in columns (3)-(4) of Table 8. As indicated by the estimation results, the launch of global budgets has no positive effect on the treatment outcomes of ischemic heart disease patients. 
All coefficient estimates are statistifally insignificant.

We now turn to the results pertaining to the treatment outcomes for hemorrhagic stroke and ischemic stroke patients, as reported in columns (5)-(6) and (7)-(8) of Table 8. The coefficient estimates pertaining to these patients are all statistically insignificant. This

implies that for patients suffering from a hemorrhagic stroke or ischemic stroke, there were no changes in their treatment outcomes, no matter whether they were admitted to for-profit or not-for-profit hospitals.

In summary, the estimation results imply that there is not very much improvement in the treatment outcomes either in for-profit or not-for-profit hospitals. This is surprising given that there was a substantial increase the intensity of treatment, especially for for-profit hospitals. For example, even though there was a $17.9 \%$ and $12.2 \%$ increase in treatment intensity for $\mathrm{AMI}$ and ischemic heart disease patients, there was no substantial improvement in these patients' mortality or re-admission rates. This implies that while the launch of global budgets encouraged for-profit hospitals to supply more medical services to each patient, this increase has yield not much improvement in treatment outcomes.

\section{Conclusion}

This study is devoted to investigating the impact of hospital global budgeting on treatment intensity and outcomes of AMI, ischemic heart disease, hemorrhagic stroke, and ischemic stroke patients. In most western developed and other high income countries, where medical services are usually reimbursed through public health insurance, global budgeting is prevalent in containing increasing health care costs, and it is shown to be effective in doing so.

Theoretical studies predict that, under reasonable assumptions, medical providers will increase the quantity of services, see Fan et al. (1998) and Benstetter and Wambach (2006). This is largely due to providers' failure to coordinate among each other in order to achieve a global optimal solution such that they pursue a income targeting strategy. 
Except providers' decision concerning the quantity of service, previous studies in the literature seldom touch on other important issues. For example, it is important to study the impact of global budgeting on patients' welfare (e.g., treatment outcomes, out-of-pocket expenditure, accessibility of services, etc.). It is well established that global budgeting is effective in containing cost. However, if global budgeting's success in cost containment comes at the expense of patients' welfare, then health authorities ought to consider alternative cost containment measures or design mechanisms to ensure that patients' welfare is not jeopardized. Furthermore, an important issue which is worth exploring is whether global budgeting leads to a waste of medical resources. If gl obal budgeting led an increase in the intensity of treatment, but this increase was not accompanied by an improvement in treatment outcomes, then there is likely to be a waste of medical resources. This study seek answers to these questions by exploring global budgeting's impact on treatment intensity and outcomes.

This study uses the case of Taiwan, where National Health I nsurance was implemented in 1995 to cover all residents and hospital global budgeting was installed in 2002 to contain rising health care cost. Our empirical analysis is based on the National Health Insurance claim records. Our data consist of the universe of patients hospitalized due to AMI, ischemic heart disease, hemorrhagic stroke, or an ischemic stroke in Taiwan during the period 20002005. To measure treatment intensity, we use the number of units (i.e., "points") of medical services that a hospital applies to a patient.

In our empirical analysis, we divide hospitals into two types: for-profit and not-for-profit hospitals. This is based on our conjecture that due to profit incentive, for-profit hospitals will adjust their behavior in response to global budgeting, which changes the marginal profit of service provision. Because profit maximization is not the utmost objective of not-for-profit hospitals, they are expected to be sluggish in responding to global budgeting.

Our empirical results suggests that there is a large increase in for-profit hospitals' treatment intensity, especially for patients suffering from AMI and ischemic heart disease. However, there is only very slight improvements in treatment outcomes for patients in for-profit hospitals in terms of post-discharge readmission and mortality. We find that for AMI pa- 
tients admitted to a for-profit hospital, global budgeting reduced the 30 day post-discharge readmission 5.506 percentage points. Using the 2001 AMI patients' readmission rates of $14.47 \%$ as a benchmark, this represents a $38.05 \%$ reduction. However, there is no statistically significant change in treatment outcomes for these AMI patients' 7, 30, and 90 day mortality rates. For for-profit hospital patients suffering from other diseases, there are no discernible improvements their treatment outcomes.

For not-for-profit hospitals, the treatment outcomes for AMI, ischemic heart disease, hemorrhagic stroke, and ischemic stroke patients are not affected. This is consistent with our a priori conjecture.

Overall, our results suggests that there was a substantial increase in treatment intensity accompanied by the launch of global budgeting. However, this increase in treatment intensity has only led to a slight improvement in treatment outcomes. These results indicate that the increased medical care devoted to treatment represents a misallocation or waste of resources. This implies that aggregate expenditure caps should be supplemented by other designs to prevent resources misallocation. For example, Benstetter and Wambach's (2006) suggestion of setting a minimum price for medical services may all eviate the excess use of medical resources. Alternatively, on top of global budget, a DRG-based payment system instead of a medical procedure-based fee-for-service payment system may prevent hospitals from providing unnecessary medical services to patients. 
Table 2: Number of different types of hospitals

\begin{tabular}{ccccc}
\hline \hline \multirow{2}{*}{ Year } & \multicolumn{4}{c}{ Number of Hospitals } \\
\cline { 2 - 5 } & Public & $\begin{array}{c}\text { Private } \\
\text { Not-For-Profit }\end{array}$ & For-Profit & Total \\
\hline 1998 & 95 & 55 & 497 & 647 \\
1999 & 96 & 57 & 481 & 634 \\
2000 & 94 & 59 & 464 & 617 \\
2001 & 92 & 59 & 442 & 593 \\
2002 & 91 & 61 & 422 & 574 \\
2003 & 91 & 61 & 406 & 558 \\
2004 & 88 & 63 & 405 & 556 \\
2005 & 79 & 66 & 386 & 531 \\
2006 & 79 & 69 & 375 & 523 \\
2007 & 79 & 76 & 352 & 507 \\
2008 & 79 & 88 & 326 & 493 \\
\hline \hline
\end{tabular}


Table 3: Number of points earned by hospitals per patient*

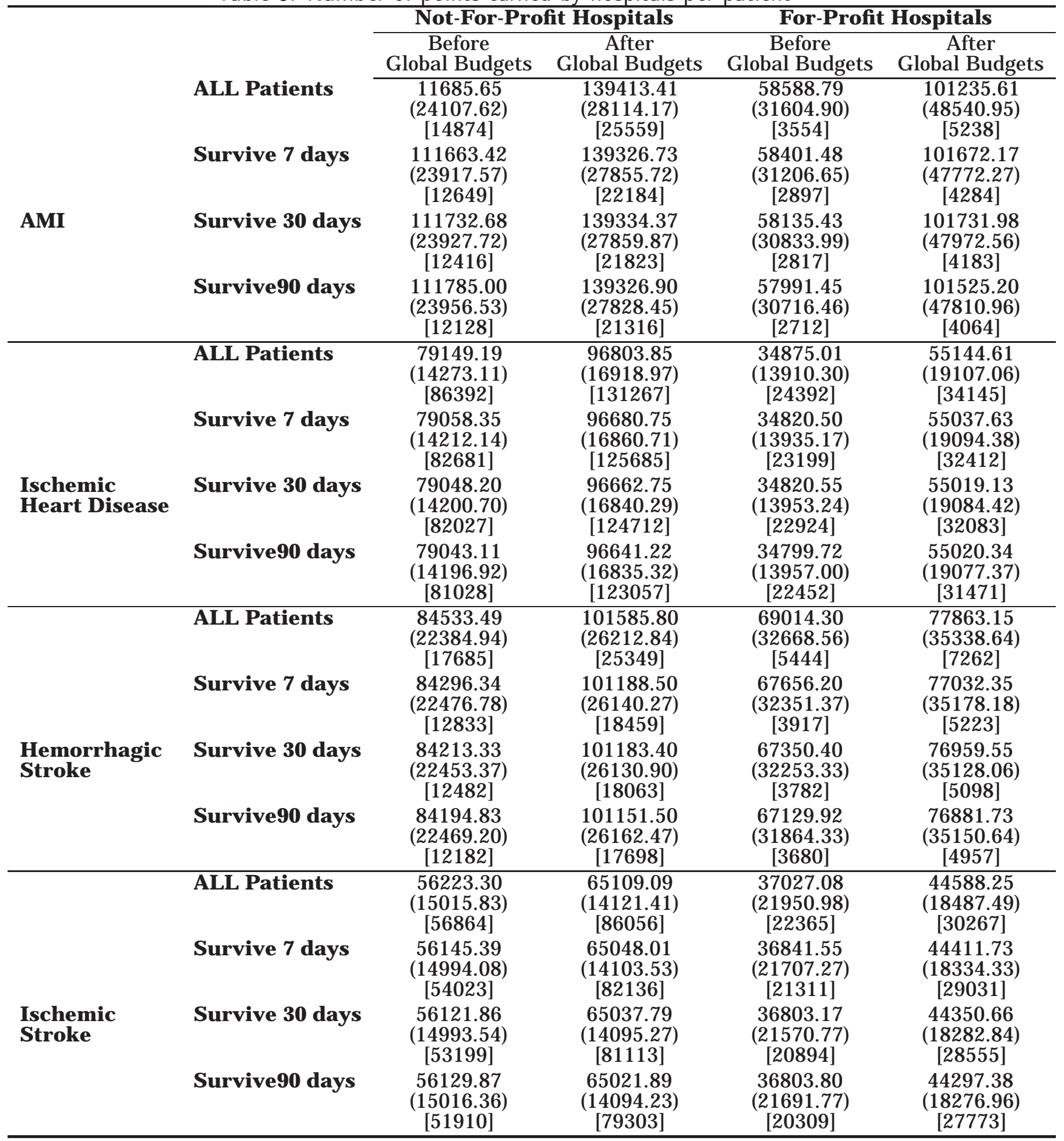

\footnotetext{
*Standard errors in parentheses and number of observations in square brackets.
} 
Table 5: Mortality Rates*

\begin{tabular}{|c|c|c|c|c|c|}
\hline & \multirow[b]{2}{*}{ Mortality rates } & \multicolumn{2}{|c|}{ Not-For-Profit Hospitals } & \multicolumn{2}{|c|}{ For-Profit Hospitals } \\
\hline & & $\begin{array}{c}\text { Before } \\
\text { Global Budgets }\end{array}$ & $\begin{array}{c}\text { After } \\
\text { Global Budgets }\end{array}$ & $\begin{array}{c}\text { Before } \\
\text { Global Budgets }\end{array}$ & $\begin{array}{c}\text { After } \\
\text { Global Budgets }\end{array}$ \\
\hline \multirow{4}{*}{ AMI } & 7-day & $\begin{array}{l}0.166 \\
(0.37)\end{array}$ & $\begin{array}{l}0.15 \\
(0.36)\end{array}$ & $\begin{array}{l}0.201 \\
(0.40)\end{array}$ & $\begin{array}{l}0.208 \\
(0.41)\end{array}$ \\
\hline & 30-day & $\begin{array}{l}0.185 \\
(0.39)\end{array}$ & $\begin{array}{l}0.166 \\
(0.37)\end{array}$ & $\begin{array}{l}0.225 \\
(0.42)\end{array}$ & $\begin{array}{l}0.229 \\
(0.42)\end{array}$ \\
\hline & 90-day & $\begin{array}{l}0.207 \\
(0.40)\end{array}$ & $\begin{array}{l}0.191 \\
(0.39)\end{array}$ & $\begin{array}{l}0.257 \\
(0.44)\end{array}$ & $\begin{array}{l}0.256 \\
(0.44)\end{array}$ \\
\hline & Observations & 16247 & 23500 & 3876 & 4837 \\
\hline \multirow{4}{*}{$\begin{array}{l}\text { Ischemic Heart } \\
\text { Disease }\end{array}$} & 7-day & $\begin{array}{l}0.043 \\
(0.20)\end{array}$ & $\begin{array}{l}0.043 \\
(0.20)\end{array}$ & $\begin{array}{l}0.049 \\
(0.22)\end{array}$ & $\begin{array}{l}0.052 \\
(0.22)\end{array}$ \\
\hline & 30-day & $\begin{array}{l}0.051 \\
(0.22)\end{array}$ & $\begin{array}{l}0.050 \\
(0.22)\end{array}$ & $\begin{array}{l}0.060 \\
(0.24)\end{array}$ & $\begin{array}{l}0.062 \\
(0.24)\end{array}$ \\
\hline & 90-day & $\begin{array}{l}0.062 \\
(0.24)\end{array}$ & $\begin{array}{l}0.062 \\
(0.24)\end{array}$ & $\begin{array}{l}0.080 \\
(0.27)\end{array}$ & $\begin{array}{l}0.081 \\
(0.27)\end{array}$ \\
\hline & Observations & 86392 & 108300 & 24392 & 27659 \\
\hline \multirow{4}{*}{$\begin{array}{l}\text { Hemorrhagic } \\
\text { Stroke }\end{array}$} & 7-day & $\begin{array}{l}0.227 \\
(0.42)\end{array}$ & $\begin{array}{l}0.217 \\
(0.41)\end{array}$ & $\begin{array}{l}0.257 \\
(0.44)\end{array}$ & $\begin{array}{l}0.251 \\
(0.43)\end{array}$ \\
\hline & 30-day & $\begin{array}{l}0.246 \\
(0.43)\end{array}$ & $\begin{array}{l}0.232 \\
(0.42)\end{array}$ & $\begin{array}{l}0.280 \\
(0.45)\end{array}$ & $\begin{array}{l}0.267 \\
(0.44)\end{array}$ \\
\hline & 90-day & $\begin{array}{l}0.266 \\
(0.44)\end{array}$ & $\begin{array}{l}0.249 \\
(0.43)\end{array}$ & $\begin{array}{l}0.302 \\
(0.46)\end{array}$ & $\begin{array}{l}0.29 \\
(0.45)\end{array}$ \\
\hline & Observations & 22988 & 27961 & 6282 & 6965 \\
\hline \multirow{4}{*}{ Ischemic Stroke } & 7-day & $\begin{array}{l}0.050 \\
(0.22)\end{array}$ & $\begin{array}{l}0.046 \\
(0.21)\end{array}$ & $\begin{array}{l}0.046 \\
(0.21)\end{array}$ & $\begin{array}{l}0.040 \\
(0.20)\end{array}$ \\
\hline & 30-day & $\begin{array}{l}0.065 \\
(0.25)\end{array}$ & $\begin{array}{l}0.057 \\
(0.23)\end{array}$ & $\begin{array}{l}0.065 \\
(0.25)\end{array}$ & $\begin{array}{l}0.056 \\
(0.23)\end{array}$ \\
\hline & 90-day & $\begin{array}{l}0.087 \\
(0.28)\end{array}$ & $\begin{array}{l}0.078 \\
(0.27)\end{array}$ & $\begin{array}{l}0.092 \\
(0.29)\end{array}$ & $\begin{array}{l}0.082 \\
(0.27)\end{array}$ \\
\hline & Observations & 56855 & 88169 & 22339 & 31006 \\
\hline
\end{tabular}

* Standard errors in parentheses. 
Table 6: Descriptive Statistics*

\begin{tabular}{|c|c|c|c|c|c|}
\hline & & \multicolumn{2}{|c|}{ Not-For-Profit Hospitals } & \multicolumn{2}{|c|}{ For-Profit Hospitals } \\
\hline & & $\begin{array}{c}\text { Before } \\
\text { Global Budgets }\end{array}$ & $\begin{array}{c}\text { After } \\
\text { Global Budgets }\end{array}$ & $\begin{array}{c}\text { Before } \\
\text { Global Budgets }\end{array}$ & $\begin{array}{c}\text { After } \\
\text { Global Budgets }\end{array}$ \\
\hline \multirow{5}{*}{ AMI } & Patient Age & $\begin{array}{l}66.067 \\
(13.19)\end{array}$ & $\begin{array}{l}66.452 \\
(13.53)\end{array}$ & $\begin{array}{c}66.57 \\
(13.60)\end{array}$ & $\begin{array}{c}67.22 \\
(13.88)\end{array}$ \\
\hline & Male Patient & $\begin{array}{l}0.967 \\
(0.18)\end{array}$ & $\begin{array}{l}0.963 \\
(0.19)\end{array}$ & $\begin{array}{l}0.968 \\
(0.18)\end{array}$ & $\begin{array}{l}0.974 \\
(0.16)\end{array}$ \\
\hline & Region $\mathrm{HHI}$ & $\begin{array}{l}445.664 \\
(206.69\end{array}$ & $\begin{array}{l}434.454 \\
(194.48)\end{array}$ & $\begin{array}{l}459.316 \\
(176.94\end{array}$ & $\begin{array}{l}457.727 \\
(152.59)\end{array}$ \\
\hline & CCI Score & $\begin{array}{l}1.497) \\
(1.86\end{array}$ & $\begin{array}{l}1.659 \\
(1.92)\end{array}$ & $\begin{array}{l}1.569 \\
(1.90)\end{array}$ & $\begin{array}{l}1.79 \\
(1.92)\end{array}$ \\
\hline & Observation & 16021 & 23054 & 3836 & 4775 \\
\hline \multirow{5}{*}{$\begin{array}{l}\text { Ischemic } \\
\text { Heart Disease }\end{array}$} & Patient Age & $\begin{array}{l}66.101 \\
(11.97)\end{array}$ & $\begin{array}{l}66.153 \\
(12.46)\end{array}$ & $\begin{array}{l}66.674 \\
(13.17)\end{array}$ & $\begin{array}{l}66.873 \\
(13.25)\end{array}$ \\
\hline & Male Patient & $\begin{array}{l}0.969 \\
(0.17)\end{array}$ & $\begin{array}{l}0.968 \\
(0.18)\end{array}$ & $\begin{array}{l}0.978 \\
(0.15)\end{array}$ & $\begin{array}{l}0.979 \\
(0.14)\end{array}$ \\
\hline & Region HHI & $\begin{array}{l}427.564 \\
(202.79)\end{array}$ & $\begin{array}{l}416.431 \\
(188.89)\end{array}$ & $\begin{array}{l}433.759 \\
(176.29)\end{array}$ & $\begin{array}{l}437.542 \\
(154.97)\end{array}$ \\
\hline & $\mathrm{CCl}$ Score & $\begin{array}{l}1.494 \\
(1.79)\end{array}$ & $\begin{array}{l}1.607 \\
(1.82)\end{array}$ & $\begin{array}{l}1.626 \\
(1.87)\end{array}$ & $\begin{array}{l}1.72 \\
(1.92)\end{array}$ \\
\hline & Observation & 85675 & 107198 & 24240 & 27477 \\
\hline \multirow{5}{*}{$\begin{array}{l}\text { Hemorrhagic } \\
\text { Stroke }\end{array}$} & Patient Age & $\begin{array}{l}61.636 \\
(15.42)\end{array}$ & $\begin{array}{c}62.37 \\
(15.29)\end{array}$ & $\begin{array}{l}62.454 \\
(14.64)\end{array}$ & $\begin{array}{l}62.715 \\
(14.65)\end{array}$ \\
\hline & Male Patient & $\begin{array}{l}0.921 \\
(0.27)\end{array}$ & $\begin{array}{l}0.927 \\
(0.26)\end{array}$ & $\begin{array}{l}0.985 \\
(0.12)\end{array}$ & $\begin{array}{l}0.981 \\
(0.14)\end{array}$ \\
\hline & Region HHI & $\begin{array}{l}455.189 \\
(217.57)\end{array}$ & $\begin{array}{l}436.974 \\
(203.01)\end{array}$ & $\begin{array}{c}458.39 \\
(185.03)\end{array}$ & $\begin{array}{l}443.517 \\
(159.55)\end{array}$ \\
\hline & CCI Score & $\begin{array}{l}1.202 \\
(1.66)\end{array}$ & $\begin{array}{l}1.17 \\
(1.69)\end{array}$ & $\begin{array}{l}1.103 \\
(1.60)\end{array}$ & $\begin{array}{l}1.169 \\
(1.75)\end{array}$ \\
\hline & Observation & 22284 & 26885 & 6114 & 6641 \\
\hline \multirow{5}{*}{$\begin{array}{l}\text { Ischemic } \\
\text { Stroke }\end{array}$} & Patient Age & $\begin{array}{l}68.769 \\
(11.83)\end{array}$ & $\begin{array}{l}69.000 \\
(12.28)\end{array}$ & $\begin{array}{l}69.276 \\
(11.49)\end{array}$ & $\begin{array}{l}69.725 \\
(11.93)\end{array}$ \\
\hline & Male Patient & $\begin{array}{c}0.85 \\
(0.35)\end{array}$ & $\begin{array}{l}0.848 \\
(0.36)\end{array}$ & $\begin{array}{l}0.937 \\
(0.24)\end{array}$ & $\begin{array}{l}0.943 \\
(0.23)\end{array}$ \\
\hline & Region HHI & $\begin{array}{l}444.863 \\
(210.15\end{array}$ & $\begin{array}{l}457.130 \\
(209.67)\end{array}$ & $\begin{array}{l}479.815 \\
(180.67)\end{array}$ & $\begin{array}{l}474.634 \\
(172.16)\end{array}$ \\
\hline & CCI Score & $\begin{array}{l}1.779 \\
(1.88)\end{array}$ & $\begin{array}{l}1.727 \\
(1.85)\end{array}$ & $\begin{array}{l}1.705 \\
(1.90)\end{array}$ & $\begin{array}{l}1.84 \\
(1.92)\end{array}$ \\
\hline & Observation & 55874 & 86046 & 22101 & 30441 \\
\hline
\end{tabular}

*Standard errors in parentheses. 
Table 7: Impact of global budgets on treatment intensity ${ }^{\dagger}$

\begin{tabular}{|c|c|c|c|c|c|c|c|c|c|}
\hline \multirow{3}{*}{ Sample } & & \multicolumn{2}{|c|}{ AMI } & \multicolumn{2}{|c|}{$\begin{array}{c}\text { Ischemic Heart } \\
\text { Disease }\end{array}$} & \multicolumn{2}{|c|}{$\begin{array}{c}\text { Hemorrhagic } \\
\text { Stroke }\end{array}$} & \multicolumn{2}{|c|}{ Ischemic Stroke } \\
\hline & & Not-fc & For-pro & Not-for- & For-profit & Not-for- & For-profit & Not-for- & For-profit \\
\hline & & (1) & (2) & (3) & (4) & (5) & (6) & (7) & (8) \\
\hline \multirow[t]{2}{*}{$\begin{array}{l}\text { All } \\
\text { Patients }\end{array}$} & $\begin{array}{l}\text { I mpact of } \\
\text { Global Budget }\end{array}$ & $\begin{array}{l}0.072 * * \\
(2.59)\end{array}$ & $\begin{array}{c}0.179 * * \\
(2.72)\end{array}$ & $\begin{array}{l}0.031 \\
(1.59)\end{array}$ & $\begin{array}{l}0.122 * * \\
(2.83)\end{array}$ & $\begin{array}{l}0.085 \\
(1.31)\end{array}$ & $\begin{array}{l}0.05 \\
(1.22)\end{array}$ & $\begin{array}{r}0.017 \\
(0.80)\end{array}$ & $\begin{array}{l}0.028 \\
(1.08)\end{array}$ \\
\hline & Observation & 35901 & 7399 & 169828 & 42901 & 47354 & 11418 & 139176 & 50005 \\
\hline \multirow[t]{2}{*}{$\begin{array}{l}\text { Survive } \\
7 \text { days }\end{array}$} & $\begin{array}{l}\text { Impact of } \\
\text { Global Budget }\end{array}$ & $\begin{array}{l}0.059 * * \\
=(2.24)\end{array}$ & $\begin{array}{c}0.213^{* *} \\
(2.86)\end{array}$ & $\begin{array}{l}0.029 \\
(1.48)\end{array}$ & $\begin{array}{c}0.117 * * \\
(2.66)\end{array}$ & $\begin{array}{l}0.074 \\
(0.95)\end{array}$ & $\begin{array}{c}0.129 * * \\
(2.59)\end{array}$ & $\begin{array}{l}0.021 \\
(0.87)\end{array}$ & $\begin{array}{l}0.034 \\
(1.34)\end{array}$ \\
\hline & Observation & 30083 & 5754 & 162018 & 40486 & 36463 & 8306 & 132585 & 47864 \\
\hline \multirow[t]{2}{*}{$\begin{array}{l}\text { Survive } \\
30 \text { days }\end{array}$} & $\begin{array}{l}\text { Impact of } \\
\text { Global Budget }\end{array}$ & $\begin{array}{l}0.061 * * \\
(2.26)\end{array}$ & $\begin{array}{c}0.233 * * \\
(3.10)\end{array}$ & $\begin{array}{l}0.027 \\
(1.35)\end{array}$ & $\begin{array}{c}0.116 * * \\
(2.65)\end{array}$ & $\begin{array}{r}0.079 \\
(1.04)\end{array}$ & $\begin{array}{l}0.125 * * \\
(2.49)\end{array}$ & $\begin{array}{c}0.02 \\
(0.81)\end{array}$ & $\begin{array}{l}0.036 \\
(1.40)\end{array}$ \\
\hline & Observation & 29456 & 5582 & 160672 & 39973 & 35633 & 8069 & 130801 & 46994 \\
\hline \multirow[t]{2}{*}{$\begin{array}{l}\text { Survive } \\
90 \text { days }\end{array}$} & $\begin{array}{l}\text { Impact of } \\
\text { Global Budget }\end{array}$ & $\begin{array}{l}0.059 * * \\
(2.22)\end{array}$ & $\begin{array}{l}0.252^{* *} \\
(3.21)\end{array}$ & $\begin{array}{l}0.026 \\
(1.29)\end{array}$ & $\begin{array}{l}0.117 * * \\
(2.64)\end{array}$ & $\begin{array}{l}0.077 \\
(1.02)\end{array}$ & $\begin{array}{l}0.128 * * \\
(2.56)\end{array}$ & $\begin{array}{l}0.017 \\
(0.70)\end{array}$ & $\begin{array}{l}0.037 \\
(1.40)\end{array}$ \\
\hline & Observation & 28594 & 5355 & 158439 & 39054 & 34765 & 7822 & 127809 & 45693 \\
\hline
\end{tabular}

tt-statistic in parentheses.

** Statistically significant at the $5 \%$ level.

* Statistically significant at the $10 \%$ level.

Table 8: Effect of global budgets on treatment outcomes ${ }^{\dagger}$

\begin{tabular}{|c|c|c|c|c|c|c|c|c|}
\hline \multirow{3}{*}{$\begin{array}{l}\text { Treatment } \\
\text { Outcomes }\end{array}$} & \multicolumn{2}{|c|}{$\overline{A M}$} & \multicolumn{2}{|c|}{$\begin{array}{c}\text { Ischemic Heart } \\
\text { Disease }\end{array}$} & \multicolumn{2}{|c|}{$\begin{array}{l}\text { Hemorrhaqic } \\
\text { Stroke }\end{array}$} & \multicolumn{2}{|c|}{ Ischemic Stroke } \\
\hline & $\begin{array}{l}\text { Not-for } \\
\text { profit }\end{array}$ & $r-p r$ & $\begin{array}{l}\text { Not-for- } \\
\text { profit }\end{array}$ & or-profit & $\begin{array}{l}\text { Not-for- } \\
\text { profit }\end{array}$ & For-profit & $\begin{array}{l}\text { Not-for- } \\
\text { profit }\end{array}$ & \\
\hline & 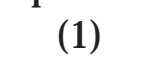 & (2) & (3) & (4) & (5) & (6) & (7) & (8) \\
\hline \multirow[t]{2}{*}{$\begin{array}{l}\text { 30-Day } \\
\text { Readmission }\end{array}$} & $\begin{array}{l}-0.097 \\
(-0.15)\end{array}$ & $\begin{array}{l}-5.506 * \\
(-1.76)\end{array}$ & $\begin{array}{l}-0.485 \\
(-0.73)\end{array}$ & $\begin{array}{l}-2.795 \\
(-1.62)\end{array}$ & $\begin{array}{l}-0.061 \\
(-0.18)\end{array}$ & $\begin{array}{l}-1.57 \\
(-1.49)\end{array}$ & $\begin{array}{l}-0.163 \\
(-0.49)\end{array}$ & $\begin{array}{l}0.194 \\
(0.32)\end{array}$ \\
\hline & [32833] & [6733] & [38181] & [9522] & [184758] & [48828] & [135308] & [49899] \\
\hline 7-D & $\begin{array}{l}-0.216 \\
(-0.44)\end{array}$ & $\begin{array}{l}-1.737 \\
(-1.54)\end{array}$ & $\begin{array}{l}0.347 \\
(0.66)\end{array}$ & $\begin{array}{l}-0.835 \\
(-0.95)\end{array}$ & $\begin{array}{c}-0.17 \\
(-1.63)\end{array}$ & $\begin{array}{l}0.032 \\
(0.14)\end{array}$ & $\begin{array}{l}-0.076 \\
(-0.58)\end{array}$ & \\
\hline 30-Day Mo & $\begin{array}{l}-0.368 \\
(-0.58)\end{array}$ & $\begin{array}{l}-1.324 \\
(-0.94)\end{array}$ & $\begin{array}{l}0.100 \\
(0.16)\end{array}$ & $\begin{array}{l}-1.621 \\
(-1.64)\end{array}$ & $\begin{array}{l}-0.019 \\
(-0.13)\end{array}$ & $\begin{array}{l}0.041 \\
(0.11)\end{array}$ & $\begin{array}{l}-0.131 \\
(-0.62)\end{array}$ & $\begin{array}{l}-0.224 \\
(-0.54)\end{array}$ \\
\hline \multirow[t]{2}{*}{ 90-Day Mortality } & $\begin{array}{l}-0.045 \\
(-0.06)\end{array}$ & $\begin{array}{l}-1.715 \\
(-1.00)\end{array}$ & $\begin{array}{l}-0.059 \\
(-0.09)\end{array}$ & $\begin{array}{l}-1.014 \\
(-1.05)\end{array}$ & $\begin{array}{l}-0.049 \\
(-0.28)\end{array}$ & $\begin{array}{l}0.258 \\
(0.48)\end{array}$ & $\begin{array}{l}-0.104 \\
(-0.46)\end{array}$ & $\begin{array}{l}-0.047 \\
(-0.08)\end{array}$ \\
\hline & [30788] & [5984] & [37228] & [8631] & [163216] & [40918] & [133167] & [48309] \\
\hline
\end{tabular}

\footnotetext{
${ }^{\dagger}$ All coefficients are multiplied by 100 . t-statistics in parentheses.

** Statistically significant at the $5 \%$ level.

* Statistically significant at the $10 \%$ level.
} 


\section{References}

[1] Benstetter, F. and Wambach, A. (2006), "The treadmill effect in a fixed budget system," J ournal of Health Economics, 25, 146-169.

[2] Chen, F.J , J .N. Laditka, S.B. SLaditka, S. Xirasagar (2007) “Providers' Response to global budgeting in Taiwan: What were the initial effects?" Health Service Management Research, 20, 113-120.

[3] Cheng, S.-H, C.-C. Chen and W.-L. Chang (2009), “Hospital response to a global budget program under universal health insurance in Taiwan," Health Policy, 92(2-3), 158- 164.

[4] Docteur, E. and H. Oxley (2004), "Health-System Reform: Lessons from Experience" in Towards High-Performing Health Systems, OECD Policy Studies, Paris: Organisation for Economic Co-Operation and Development.

[5] Fan, C. P., Chen, K.P., and Kan, K. (1998), “The design of payment systems for physicians under gl obal budget- an experimental study," J ournal of Economic Behavior and Organization, 34(2), 295-311.

[6] Fan, J . and I. Gijbels (1996), Local Polynomial Modelling and Its Applications, London: Chapman \& Hall.

[7] Feldman, R. and F. Lobo (1997), “Global budgets and excess demand for hospital care," Health Economics, 6(2), 187-196.

[8] Hurley, J., J . Lomas, and L.J . Goldsmith (1997), “Physician responses to gl obal physician expenditure budgets in Canada: A common property perspective," The Milbank Quarterly, 75(3), 343-364.

[9] Le Grand, J . (2003), “M ethods of cost containment: Some lessons from E urope," Working Paper, London School of Economics.

[10] Lee, D.S. and T. Lemieux (2010), "Regression Discontinuity Designs in Economics," J ournal of Economic Literature, 48, 281-355. 
[11] Lee, M.C. and A.M. J ones, (2004), "How did dentists respond to the introduction of gl obal budgets in Taiwan? An Evaluation Using Individual Panel Data," International J ournal of Health Care Finance and Economics, 4, 307-326.

[12] Mougeot, M. and F. Naegelen (2005), "Hospital price regulation and expenditure cap policy," J ournal of Health Economics, 24, 55-72.

[13] Phelps, C.E. (2009), Health Economics, 4nd ed. Boston: Addison-Wesley Educational Publishers, 432-435.

[14] Rochaix, L. (1993), "Financial Incentives for Physicians: the Quebec Experience," Health Economics, 2, 163-176.

[15] U.S. Department of J ustice and the Federal Trade Commission (1997), Horizontal Merger Guidelines, U.S. Government Printing Office.

[16] Wolfe, P.R and D.W. Moran (1993), "Global budgeting in the OECD countries," Health Care Financing Review, 14(3), 55-76. 